Board of Governors of the Federal Reserve System

International Finance Discussion Papers

Number 655

December 1999

\title{
DISTRIBUTIONS OF ERROR CORRECTION TESTS FOR COINTEGRATION
}

Neil R. Ericsson and James G. MacKinnon

NOTE: International Finance Discussion Papers are preliminary materials circulated to stimulate discussion and critical comment. References to International Finance Discussion Papers (other than an acknowledgment that the writer has had access to unpublished material) should be cleared with the author or authors. Recent IFDPs are available on the Web at www.bog.frb.fed.us. 


\title{
DISTRIBUTIONS OF ERROR CORRECTION TESTS FOR COINTEGRATION
}

\author{
Neil R. Ericsson and James G. MacKinnon*
}

Abstract: This paper provides cumulative distribution functions, densities, and finite sample critical values for the single-equation error correction statistic for testing cointegration. Graphs and response surfaces summarize extensive Monte Carlo simulations and highlight simple dependencies of the statistic's quantiles on the number of variables in the error correction model, the choice of deterministic components, and the estimation sample size. The response surfaces provide a convenient way for calculating finite sample critical values at standard levels; and a computer program, freely available over the Internet, can be used to calculate both critical values and $p$-values. Three empirical examples illustrate these tools.

Keywords: cointegration, critical value, distribution function, error correction, Monte Carlo, response surface.

JEL classifications: C22, C52.

${ }^{*}$ The first author is a staff economist in the Division of International Finance, Board of Governors of the Federal Reserve System, Washington, D.C. 20551 U.S.A., and the second author is the Sir Edward Peacock Professor of Econometrics in the Department of Economics, Queen's University, Kingston, Ontario, Canada K7L 3NS. The authors may be reached on the Internet at ericsson@frb.gov and jgm@qed.econ.queensu.ca respectively. The views in this paper are solely the responsibility of the authors and should not be interpreted as reflecting the views of the Board of Governors of the Federal Reserve System or of any other person associated with the Federal Reserve System. The second author's research was supported in part by grants from the Social Sciences and Humanities Research Council of Canada. An earlier version of this paper appeared under the title "Finite Sample Properties of Error Correction Tests for Cointegration". We are grateful to Shaghil Ahmed, David Bowman, Jon Faust, David Hendry, Søren Johansen, Fred Joutz, Andy Levin, Jaime Marquez, Bent Nielsen, and John Rogers for helpful comments and discussion; to Hayden Smith and Sebastian Thomas for research assistance; and to Jurgen Doornik and David Hendry for providing us with a beta-test version of GiveWin Version 2.0. Monte Carlo simulations and the graphs of the cumulative distribution functions and densities were obtained from modified versions of programs for MacKinnon $(1994,1996)$. Response surfaces were obtained using PcGive Professional Version 9.2, and 3D graphics were generated from GiveWin: see Doornik and Hendry (1996). The paper's tables of response surface coefficients and the computer program for calculating critical values and $p$-values are available from the second author's home page (http://www.econ.queensu.ca/pub/faculty/mackinnon/). 


\section{Introduction}

Three general approaches are widely used for testing whether or not nonstationary economic time series are cointegrated: single-equation static regressions, due to Engle and Granger (1987); vector autoregressions, as formulated by Johansen $(1988,1991)$; and single-equation conditional error correction models, initially proposed by Phillips (1954, 1957) and further developed by Sargan (1964). While all three have their advantages and disadvantages, testing for cointegration with any of these approaches requires nonstandard critical values, which usually are calculated by Monte Carlo simulation. Engle and Granger (1987) tabulate a limited set of critical values for their procedure. MacKinnon (1991) derives a more extensive set with finite sample corrections based on response surfaces, and MacKinnon (1996) provides a computer program to calculate critical values for Engle and Granger's test at any desired level. Johansen (1988), Johansen and Juselius (1990), and Osterwald-Lenum (1992) include critical values for the Johansen procedure under typical assumptions about deterministic terms and the number of stochastic variables. Johansen (1995), Doornik (1998, 1999), and MacKinnon, Haug, and Michelis (1999) provide more accurate estimates of these critical values, with the last of these papers also providing computer programs to calculate critical values and $p$-values.

By contrast, critical values for the single-equation error correction procedure are scant, perhaps because error correction models substantially predate the literature on cointegration. Banerjee, Dolado, Galbraith, and Hendry (1993) tabulate critical values for an error correction model with two variables at three sample sizes; and Banerjee, Dolado, and Mestre (1998) list critical values for models with two through six variables at five sample sizes. Harbo, Johansen, Nielsen, and Rahbek (1998), MacKinnon, Haug, and Michelis (1999), and Pesaran, Shin, and Smith (1999) list asymptotic critical values for a related but distinct procedure for single- and multipleequation error correction models.

The current paper addresses this dearth by providing an extensive set of cointegration critical values for the single-equation error correction model. These critical values include finite sample adjustments similar to those in MacKinnon $(1991,1996)$ for the Engle-Granger procedure, they are very accurate numerically and are easy to use in practice, and they encompass and supercede comparable results in Banerjee, Dolado, Galbraith, and Hendry (1993) and Banerjee, Dolado, and Mestre (1998). We also provide a freely available program, similar to the one in MacKinnon (1996) for

the Engle-Granger procedure, that computes both critical values and $p$-values for the error correction statistic. Conditional error correction models are ubiquitous empirically, so these tools for calculating critical values and $p$-values should be of immediate use to the empirical modeler. Finally, general distributional properties are of considerable interest. Accurate numerical approximations to the entire distribution of the error correction statistic are calculated herein and offer insights into the nature 
of that statistic, particularly relative to the Dickey-Fuller and Engle-Granger statistics. Graphs highlight the error correction statistic's properties and relationships, and show for the first time what many of its various distributions and densities look like. Throughout, the focus is on testing for cointegration, rather than on the complementary task of estimating the cointegrating vectors, assuming a given cointegration rank, as in Stock (1987), Phillips and Loretan (1991), and Stock and Watson (1993).

This paper is organized as follows. Section 2 sets the backdrop by considering the three common procedures and their relationships to each other. Section 3 outlines the structure of the Monte Carlo analysis for calculating the distributional properties of the cointegration test statistic based on the single-equation error correction model. Section 4 presents the Monte Carlo results, which include cumulative distributions, densities, and critical values with finite sample corrections. Section 5 applies the finite sample critical values derived in Section 4 and the computer program for calculating $p$-values to empirical error correction models of U.K. narrow money demand (from Hendry and Ericsson (1991)), U.K. consumers' expenditure (from Davidson, Hendry, Srba, and Yeo (1978)), and U.S. federal government debt (from Hamilton and Flavin (1986)). Section 6 concludes.

\section{An Overview of Three Test Procedures}

This paper focuses on finite sample inference about cointegration in a single-equation conditional error correction model (ECM). ${ }^{1}$ To motivate the use of conditional ECMs, this section describes the analytics of and inferential methods for the three common approaches for testing cointegration: the Johansen procedure (Section 2.1), the conditional error correction model (Section 2.2), and the Engle-Granger procedure (Section 2.3). Differences between the three approaches turn on their various assumptions about dynamics and exogeneity (Section 2.4).

\subsection{The Johansen Procedure}

Johansen $(1988,1991)$ derives a maximum likelihood procedure for testing for cointegration in a finite-order Gaussian vector autoregression (VAR). That system is:

$$
x_{t}=\sum_{i=1}^{\ell} \pi_{i} x_{t-i}+\Phi D_{t}+\varepsilon_{t} \quad \varepsilon_{t} \sim I N(0, \Omega), \quad t=1, \ldots, T,
$$

where $x_{t}$ is a vector of $k$ variables at time $t ; \pi_{i}$ is a $k \times k$ matrix of coefficients on the $i$ th lag of $x_{t}$; $\ell$ is the maximal lag length; $\Phi$ is a $k \times d$ matrix of coefficients on $D_{t}$, a vector of $d$ deterministic variables (such as a constant term and a trend); $\varepsilon_{t}$ is a vector

\footnotetext{
${ }^{1}$ Strictly speaking, the models examined herein are equilibrium correction models; see Hendry (1995a).
} 
of $k$ unobserved, sequentially independent, jointly normal errors with mean zero and (constant) covariance matrix $\Omega$; and $T$ is the number of observations. Throughout, $x$ is restricted to be (at most) integrated of order one, denoted $\mathrm{I}(1)$, where an $\mathrm{I}(j)$ variable requires $j$ th differencing to make it stationary.

The VAR in (1) may be rewritten as a vector error correction model:

$$
\Delta x_{t}=\pi x_{t-1}+\sum_{i=1}^{\ell-1} \Gamma_{i} \Delta x_{t-i}+\Phi D_{t}+\varepsilon_{t} \quad \varepsilon_{t} \sim I N(0, \Omega),
$$

where $\pi$ and $\Gamma_{i}$ are:

$$
\begin{aligned}
\pi & =\left(\sum_{i=1}^{\ell} \pi_{i}\right)-I_{k}, \\
\Gamma_{i} & =-\left(\pi_{i+1}+\cdots+\pi_{\ell}\right) \quad i=1, \ldots, \ell-1,
\end{aligned}
$$

$I_{k}$ is the identity matrix of dimension $k$, and $\Delta$ is the difference operator. ${ }^{2}$ For any specified number of cointegrating vectors $r(0 \leq r \leq k)$, the matrix $\pi$ is of (potentially reduced) rank $r$ and may be rewritten as:

$$
\pi=\alpha \beta^{\prime}
$$

where $\alpha$ and $\beta$ are $k \times r$ matrices of full rank. By substitution, (2) is:

$$
\Delta x_{t}=\alpha \beta^{\prime} x_{t-1}+\sum_{i=1}^{\ell-1} \Gamma_{i} \Delta x_{t-i}+\Phi D_{t}+\varepsilon_{t} \quad \varepsilon_{t} \sim I N(0, \Omega) .
$$

In $(6), \beta$ is the matrix of cointegrating vectors, and $\alpha$ is the matrix of "weighting elements".

Johansen $(1988,1991)$ derives two maximum likelihood statistics for testing the rank of $\pi$ in (2) and hence for testing the number of cointegrating vectors in (2). Critical values appear in Johansen (1988, Table 1) for a VAR with no deterministic components, in Johansen and Juselius (1990, Tables A1-A3) for VARs with a constant term, and in Osterwald-Lenum (1992) and Johansen (1995, Chapter 15) for VARs with no deterministic components, with a constant term only, and with a constant term and a linear trend. Doornik $(1998,1999)$ derives a convenient approximation to the maximum likelihood statistics' distributions using the Gamma distribution, and MacKinnon, Haug, and Michelis (1999) provide computer programs to calculate critical values and $p$-values for the Johansen procedure.

\footnotetext{
${ }^{2}$ The difference operator $\Delta$ is defined as $(1-L)$, where the lag operator $L$ shifts a variable one period into the past. Hence, for $x_{t}, L x_{t}=x_{t-1}$ and so $\Delta x_{t}=x_{t}-x_{t-1}$. More generally, $\Delta_{j}^{i} x_{t}=\left(1-L^{j}\right)^{i} x_{t}$ for positive integers $i$ and $j$. If $i$ or $j$ is not explicit, it is taken to be unity.
} 


\subsection{Single-equation Conditional Error Correction Models}

Without loss of generality, the VAR in (1) can be factorized into a pair of conditional and marginal models. If the marginal variables are weakly exogenous for the cointegrating vectors $\beta$, then inference about cointegration using the conditional model alone can be made without loss of information relative to inference using the full system (the VAR); see Johansen (1992a, 1992b). This subsection derives a singleequation conditional model from the VAR and delineates two related approaches for conducting such inferences about cointegration from that conditional model, where the second of those approaches is the focus of the Monte Carlo analysis in Sections 3 and 4 and of the empirical analysis in Section 5 .

For expositional clarity, assume that (1) is a first-order VAR with no deterministic components. Its explicit representation as the vector error correction model (2) is:

$$
\begin{aligned}
& \Delta y_{t}=\pi_{(11)} y_{t-1}+\pi_{(12)} z_{t-1}+\varepsilon_{1 t} \\
& \Delta z_{t}=\pi_{(21)} y_{t-1}+\pi_{(22)} z_{t-1}+\varepsilon_{2 t}
\end{aligned}
$$

where $x_{t}^{\prime}=\left(y_{t} z_{t}^{\prime}\right), y_{t}$ is a scalar endogenous variable, $z_{t}$ is a $(k-1) \times 1$ vector of potentially weakly exogenous variables, $\pi$ is partitioned conformably to $x_{t}$ as $\left\{\pi_{(i j)}\right\}$, and $\varepsilon_{t}^{\prime}=\left(\varepsilon_{1 t} \varepsilon_{2 t}^{\prime}\right)$. From (6), equations (7)-(8) may be written as:

$$
\begin{aligned}
\Delta y_{t} & =\alpha_{1} \beta^{\prime} x_{t-1}+\varepsilon_{1 t} \\
\Delta z_{t} & =\alpha_{2} \beta^{\prime} x_{t-1}+\varepsilon_{2 t},
\end{aligned}
$$

where $\alpha^{\prime}=\left(\alpha_{1} \alpha_{2}^{\prime}\right)$. Equations (9)-(10) always may be factorized into the conditional distribution of $y_{t}$ given $z_{t}$ and lags on both variables, and the marginal distribution of $z_{t}$ (also given lags on both variables):

$$
\begin{aligned}
\Delta y_{t} & =\gamma_{0}^{\prime} \Delta z_{t}+\gamma_{1} \beta^{\prime} x_{t-1}+\nu_{1 t} \\
\Delta z_{t} & =\alpha_{2} \beta^{\prime} x_{t-1}+\varepsilon_{2 t},
\end{aligned}
$$

where $\gamma_{0}^{\prime}=\Omega_{12} \Omega_{22}^{-1}, \gamma_{1}=\alpha_{1}-\Omega_{12} \Omega_{22}^{-1} \alpha_{2}, \nu_{1 t}=\varepsilon_{1 t}-\Omega_{12} \Omega_{22}^{-1} \varepsilon_{2 t}$, the expectation $\mathcal{E}\left(\nu_{1 t} \varepsilon_{2 t}\right)$ is zero (by construction), and the error covariance matrix $\Omega$ in $(1)$ is $\left\{\Omega_{i j}\right\}$. Equivalently, the error $\varepsilon_{1 t}$ in (9) may be partitioned into two uncorrelated components as $\varepsilon_{1 t}=\nu_{1 t}+\gamma_{0}^{\prime} \varepsilon_{2 t}$, and then $\varepsilon_{2 t}$ is substituted out to obtain (11).

The variable $z_{t}$ is weakly exogenous for $\beta$ if and only if $\alpha_{2}=0$ in (12), in which case (11)-(12) becomes:

$$
\begin{aligned}
\Delta y_{t} & =\gamma_{0}^{\prime} \Delta z_{t}+\gamma_{1} \beta^{\prime} x_{t-1}+\nu_{1 t} \\
\Delta z_{t} & =\varepsilon_{2 t},
\end{aligned}
$$

where $\gamma_{1}=\alpha_{1}$. The test for weak exogeneity in Johansen (1992a) is a test of $\alpha_{2}=0$.

If $\alpha_{2}=0$, the conditional ECM (13) by itself is sufficient for inference about $\beta$ that is without loss of information relative to inference from (11)-(12) together. 
Two distinct approaches have evolved for testing cointegration in the conditional ECM (13): one is due to Harbo, Johansen, Nielsen, and Rahbek (1998), and the other originates from the literature on error correction models. The current paper analyzes the second approach, and a clarification between the two approaches is central to understanding their respective properties.

Harbo, Johansen, Nielsen, and Rahbek (1998) derive the likelihood-ratio statistic for testing cointegrating rank in a conditional subsystem obtained from a Gaussian VAR when the marginal variables are weakly exogenous for $\beta$. For a single-equation conditional model such as (13), the null hypothesis being tested is $\gamma_{1} \beta^{\prime}=0$, i.e., that the cointegrating rank for $x$ is zero. The alternative hypothesis is that $\gamma_{1} \beta^{\prime} \neq 0$, implying that $x$ has a cointegrating vector $\beta$ with at least one nonzero element.

The second approach stems from the literature on error correction models and is based on transformations of (13), with an auxiliary assumption about the nature of $x$ 's cointegration. Specifically, the conditional ECM (13) can be motivated as a reparameterization of the conditional autoregressive distributed lag (ADL) model; see Davidson, Hendry, Srba, and Yeo (1978) and Hendry, Pagan, and Sargan (1984) inter alia. Data transformations imply reparameterizations, and two transformations are of particular interest:

$$
\begin{array}{lll}
\text { differencing: } & \mu_{1} x_{t}+\mu_{2} x_{t-1} \rightarrow \mu_{1} \Delta x_{t}+\left(\mu_{1}+\mu_{2}\right) x_{t-1} \\
\text { differentials: } & \mu_{1} y_{t}+\mu_{2} z_{t} \rightarrow \mu_{1}\left(y_{t}-z_{t}\right)+\left(\mu_{1}+\mu_{2}\right) z_{t},
\end{array}
$$

for arbitrary coefficients $\mu_{1}$ and $\mu_{2}$. Repeatedly applying these two transformations rearranges a conditional ADL into the conditional ECM (13):

$$
\begin{aligned}
y_{t} & =\lambda_{0}^{\prime} z_{t}+\lambda_{1}^{\prime} z_{t-1}+\lambda_{2} y_{t-1}+\nu_{1 t} \\
y_{t} & =\gamma_{0}^{\prime} \Delta z_{t}+\lambda_{3}^{\prime} z_{t-1}+\lambda_{2} y_{t-1}+\nu_{1 t} \\
\Delta y_{t} & =\gamma_{0}^{\prime} \Delta z_{t}+\lambda_{3}^{\prime} z_{t-1}+\gamma_{1} y_{t-1}+\nu_{1 t} \\
\Delta y_{t} & =\gamma_{0}^{\prime} \Delta z_{t}+\gamma_{1}\left(y_{t-1}-\delta^{\prime} z_{t-1}\right)+\nu_{1 t} \\
\Delta y_{t} & =\gamma_{0}^{\prime} \Delta z_{t}+\gamma_{1} \beta^{\prime} x_{t-1}+\nu_{1 t}
\end{aligned}
$$

where $\lambda_{0}, \lambda_{1}, \lambda_{2}, \lambda_{3}$, and $\delta$ are various coefficients; and the cointegrating vector $\beta$ has been normalized on its first coefficient (i.e., for $y)$ such that $\beta^{\prime}=\left(\begin{array}{ll}1-\delta^{\prime}\end{array}\right)$. In practice, significance testing of the error correction term typically has been based on the $t$-ratio for $\gamma_{1}$ in (17) (not in (18) or (19)): this is the "PcGive unit root test" in Hendry (1989, p. 149) and Hendry and Doornik (1996, p. 235), which here is denoted the ECM statistic.

When interpreted as a test for cointegration of $x$, this approach requires an additional assumption: namely, that the variables in $z$ are not cointegrated among themselves. Thus, $\gamma_{1}=0$ in (17) implies (and is implied by) a lack of cointegration between $y$ and $z$, whereas $\gamma_{1}<0$ implies cointegration. The $t$-ratio based upon the least squares estimator of $\gamma_{1}$ in (17) is the ECM statistic analyzed in Sections 3, 4, 
and 5. That $t$-ratio is denoted $\kappa_{d}(k)$, where $d$ indicates the deterministic components included in the ECM, or the number of such deterministic components, depending upon the context; and $k$ is the total number of variables in $x$ (not to be confused with the number of regressors in the ECM). This $t$-ratio is used to test the null hypothesis that $\gamma_{1}=0$, i.e., that $y$ and $z$ are not cointegrated. If weak exogeneity does not hold, critical values generally are affected; see Hendry (1995b).

To summarize, the ECM statistic $\kappa_{d}(k)$ is designed to detect cointegration involving $y$ in the conditional model (13). The procedure in Harbo, Johansen, Nielsen, and Rahbek (1998) is designed to detect any cointegration in $x$ in the conditional model (13), where that cointegration may include $y$ or it may be restricted to $z$ alone. While both derive from conditional models, the two statistics are testing different hypotheses. They have different distributions - even asymptotically — and so require separate tabulation.

Harbo, Johansen, Nielsen, and Rahbek (1998, Tables 2-4) present asymptotic critical values for their statistic for (typically) $k=2, \ldots, 7$ with several choices of deterministic terms, and allowing for conditional subsystems (i.e., with more than one endogenous variable) as well as conditional single equations. Pesaran, Shin, and Smith (1999, Tables T.1*-T.5*) estimate the $5 \%$ and $10 \%$ critical values for up through 5 weakly exogenous variables and 12 endogenous variables. Using response surfaces, MacKinnon, Haug, and Michelis (1999, Tables 2-6) extend and more precisely estimate the $5 \%$ critical values in Harbo, Johansen, Nielsen, and Rahbek (1998) and Pesaran, Shin, and Smith (1999) for up through 8 weakly exogenous variables and 12 endogenous variables. They also make available a program that calculates asymptotic critical values at any level and $p$-values.

Critical values for the ECM statistic $\kappa_{d}(k)$ appear in Banerjee, Dolado, Galbraith, and Hendry (1993, Table 7.6) for $k=2$ with a constant term, and in Banerjee, Dolado, and Mestre (1998, Table I) for $k=2, \ldots, 6$ with a constant term and with a constant term and a linear trend. In both articles, the maximum number of variables is too small for some empirical purposes, the estimates of the critical values are relatively imprecise, and finite sample adjustments are impractical from the reported critical values. The results in Section 4 address these limitations. In the next subsection, the derivation in (15)-(19) clarifies the relationship between the ECM and Engle-Granger procedures.

\subsection{The Engle-Granger Procedure}

Engle and Granger (1987) propose testing for cointegration by testing whether the residuals of a static regression are stationary. The usual unit root test used is that of Dickey and Fuller (1979, 1981), which is based on a finite-order autoregression. Engle and Granger's procedure imposes a common factor restriction on the dynamics of the relationship between the variables involved. If that restriction is invalid, a 
loss of power relative to the ECM and Johansen procedures may well result. This subsection highlights that role of the common factor restriction by expressing the model for Engle and Granger's procedure as a restricted ECM.

Reconsider the conditional ECM derived from a first-order VAR:

$$
\Delta y_{t}=\gamma_{0}^{\prime} \Delta z_{t}+\gamma_{1}\left(y-\delta^{\prime} z\right)_{t-1}+\nu_{1 t}
$$

where the putative disequilibrium is:

$$
w_{t}=y_{t}-\delta^{\prime} z_{t}
$$

Engle and Granger's cointegration test statistic can be formulated in terms of these two equations, thus establishing the relationship between it and the ECM statistic. Specifically, subtract $\delta^{\prime} \Delta z_{t}$ from both sides of (20) and re-arrange:

$$
\Delta\left(y-\delta^{\prime} z\right)_{t}=\gamma_{1}\left(y-\delta^{\prime} z\right)_{t-1}+\left[\left(\gamma_{0}^{\prime}-\delta^{\prime}\right) \Delta z_{t}+\nu_{1 t}\right]
$$

From the definition of $w_{t}$ in (21), equation (22) may be rewritten as:

$$
\Delta w_{t}=\gamma_{1} w_{t-1}+e_{t}
$$

where $w_{t}$ is the Engle-Granger residual and, by construction, the disturbance $e_{t}$ is:

$$
e_{t}=\left(\gamma_{0}^{\prime}-\delta^{\prime}\right) \Delta z_{t}+\nu_{1 t}
$$

The $t$-ratio on the least squares estimator of $\gamma_{1}$ in (23) is the Dickey-Fuller statistic for testing whether $w$ has a unit root and hence whether $y$ and $z$ lack (or obtain) cointegration with cointegrating vector $\left(1-\delta^{\prime}\right)$. Below, that $t$-ratio is denoted $\tau_{d}(k)$, paralleling $\hat{\tau}$ (and $\hat{\tau}_{\mu}$ and $\hat{\tau}_{\tau}$ ) in Dickey and Fuller (1979).

If the cointegrating coefficient $\delta$ is known, then the $t$-ratio on $\gamma_{1}$ in (23) has a Dickey-Fuller distribution (equivalent to assuming $k=1$ ), as originally tabulated by Dickey in Fuller (1976, Table 8.5.2). If $\delta$ is estimated by least squares prior to testing that $\gamma_{1}=0$, then other critical values are required. Engle and Granger (1987, Table II) give such critical values for the bivariate model $(k=2)$ with a constant term. The response surfaces in MacKinnon (1991, Table 1) allow construction of critical values with finite sample adjustments for $k=1, \ldots, 6$ with a constant term and with a constant term and a linear trend. MacKinnon (1996) provides a computer program to calculate numerically highly accurate critical values at any desired level for $k=1, \ldots, 12$ with deterministic terms up to and including a quadratic trend.

The $t$-ratio on $\gamma_{1}$ in (23) ignores potential information contained about $\Delta z_{t}$ in $e_{t}$, as (24) highlights. Equivalently, (22) (and so (23)) imposes the restriction $\gamma_{0}=\delta$ : namely, the short-run elasticity $\left(\gamma_{0}\right)$ equals the long-run elasticity $(\delta)$, where both elasticities are of $y$ with respect to $z$. More generally, the Engle-Granger procedure 
imposes a common factor restriction, as follows from rewriting (21) and (23) as an equilibrium relationship with an autoregressive error:

$$
y_{t}=\delta^{\prime} z_{t}+w_{t} \quad w_{t}=\left(1+\gamma_{1}\right) w_{t-1}+e_{t}
$$

Equation (25) motivates the use of unit root statistics in testing for cointegration. If $w$ has a unit root, then $\gamma_{1}=0, w$ is nonstationary, and $y$ and $z$ are not cointegrated. Conversely, if $w$ has its root inside the unit circle, then $\gamma_{1}<0, w$ is stationary, and $y$ and $z$ are cointegrated.

Nonetheless, (25) imposes a restriction on the dynamics of the relationship between $y$ and $z$. Letting $L$ be the lag operator, (25) is:

$$
\left[1-\left(1+\gamma_{1}\right) L\right] y_{t}=\left[1-\left(1+\gamma_{1}\right) L\right] \delta^{\prime} z_{t}+e_{t}
$$

where $\left[1-\left(1+\gamma_{1}\right) L\right]$ is the factor common to $y_{t}$ and $z_{t}$ (hence the name common factor restriction). Rewriting (25) as the ADL (15) or ECM (18) obtains:

$$
\begin{aligned}
y_{t} & =\delta^{\prime} z_{t}-\left(1+\gamma_{1}\right) \delta^{\prime} z_{t-1}+\left(1+\gamma_{1}\right) y_{t-1}+e_{t} \\
\text { or } \Delta y_{t} & =\delta^{\prime} \Delta z_{t}+\gamma_{1}\left(y-\delta^{\prime} z\right)_{t-1}+e_{t},
\end{aligned}
$$

highlighting the restrictiveness of the Engle-Granger procedure relative to the ECM procedure.

Even under an invalid common factor restriction, $e_{t}$ may remain white noise, as would occur in (24) if $z$ were a pure random walk. Nonetheless, $e_{t}$ would not be an innovation with respect to current and lagged $z$ and lagged $y$, noting that $e_{t}$ includes $\Delta z_{t}$. Empirically, estimated short- and long-run elasticities often differ markedly, so imposing their equality in the Engle-Granger procedure is arbitrary and hazardous. Weak exogeneity is assumed in the presentation above but is not required for the Engle-Granger procedure. See Kremers, Ericsson, and Dolado (1992) for a general derivation of the common factor restriction in the Engle-Granger procedure.

\subsection{A Comparison}

The Johansen, ECM, and Engle-Granger procedures all focus on whether or not the feedback parameters for the cointegrating vector(s) are nonzero: $\alpha$ for the Johansen procedure, $\alpha_{1}$ for the ECM procedure, and $\gamma_{1}$ (which is $\alpha_{1}$ under weak exogeneity) for the Engle-Granger procedure. The procedures differ in their assumptions about the data generation process, and those assumptions imply both advantages and disadvantages for empirical implementation. For all three procedures, numerical computations are easy and fast for both estimation and testing.

Table 1 compares the assumptions of these procedures and their implied advantages and disadvantages. For the procedure using the conditional ECM, the advantages are severalfold. The conditional ECM (or, equivalently, the unrestricted ADL) 
is a common starting point for modeling general to specific in a single-equation context. Also, weak exogeneity is often valid empirically. And, the ECM procedure is robust to many particulars of the marginal process, e.g., specific lag lengths and dynamics involved. While the ECM procedure assumes weak exogeneity and often assumes at most a single cointegrating vector, the procedure's appeal has made it common in the literature - hence the need for a clear understanding of the procedure's distributional properties. The next two sections describe the structure of the Monte Carlo analysis used for calculating such properties (Section 3) and the results obtained (Section 4).

\section{The Structure of the Monte Carlo Analysis}

The objective of this paper is to provide information on finite sample inference about cointegration in conditional error correction models. Section 2 motivated the interest in the ECM statistic by clarifying its relationships to the Johansen and Engle-Granger procedures. The remaining sections examine the distributional properties of the ECM statistic.

Because no analytical solution is known for even the asymptotic distribution of the ECM test statistic, distributional properties are estimated by Monte Carlo simulation. This section outlines the structure of that Monte Carlo simulation. Section 3.1 describes the focus of the current paper's simulation, the model estimated, and the data generation process. Sections 3.2 and 3.3 sketch the design and simulation of the Monte Carlo experiments, and Section 3.4 discusses post-simulation analysis.

\subsection{The Focus, the Model, and the Data Generation Process}

The general object of interest is the distribution of the ECM test statistic $\kappa_{d}(k)$ under the null of no cointegration. Asymptotic properties are derived in Kiviet and Phillips (1992), Campos, Ericsson, and Hendry (1996), and Banerjee, Dolado, and Mestre (1998), with certain invariance results appearing in Kiviet and Phillips (1992). Finite sample properties appear in Banerjee, Dolado, Galbraith, and Hendry (1993), Campos, Ericsson, and Hendry (1996), and Banerjee, Dolado, and Mestre (1998), but are all very limited in terms of their experimental design. ${ }^{3}$ In the current paper, two aspects are of primary concern: the cumulative distribution of the ECM statistic, and critical values at common levels of significance.

\footnotetext{
${ }^{3}$ The current paper, like much of the literature, focuses on cointegration tests when the cointegrating vectors are unknown a priori. Kremers, Ericsson, and Dolado (1992), Hansen (1995), Campos, Ericsson, and Hendry (1996), and Zivot (1996) consider distributional properties for the ECM statistic when the cointegrating coefficients are known. In that case, the statistic's distribution contains nuisance parameters, even asymptotically. Horvath and Watson (1995) and Elliott (1995) analyze properties of cointegration tests from a VAR when the cointegrating vectors are prespecified.
} 
The estimated model is the conditional ECM resulting from a possibly cointegrated, $\ell$ th-order, $k$-variable VAR, assuming weak exogeneity of $z_{t}$ for $\beta$ and with $y_{t}$ scalar. That is, the estimated model is:

$$
\Delta y_{t}=a^{\prime} \Delta z_{t}+b^{\prime} x_{t-1}+\sum_{i=1}^{\ell-1} \Gamma_{1 i} \Delta x_{t-i}+\phi_{1}^{\prime} D_{t}+\nu_{1 t} \quad \nu_{1 t} \sim I N\left(0, \sigma_{\nu}^{2}\right)
$$

where $a, b, \Gamma_{1 i}$, and $\phi_{1}$ are coefficients on $\Delta z_{t}, x_{t-1}, \Delta x_{t-i}$, and $D_{t}$ in the conditional $\mathrm{ECM}$; and $\sigma_{\nu}^{2}$ is the conditional ECM's error variance. Because $b^{\prime} \equiv\left(\begin{array}{llll}b_{1} & b_{2} & \ldots & b_{k}\end{array}\right)=$ $\gamma_{1} \beta^{\prime}$ in the notation of the ECM (19), then $b_{1}$ is $\gamma_{1}$, which is the coefficient of interest in the ECM statistic $\kappa_{d}(k)$. The deterministic component $D_{t}$ may include a constant term, a constant term and a linear trend, or a constant term, a linear trend, and a quadratic trend. The corresponding ECM statistics are denoted $\kappa_{c}(k), \kappa_{c t}(k)$, and $\kappa_{c t t}(k)$ respectively. If no variables are included in $D_{t}$, then the ECM statistic is denoted $\kappa_{n c}(k)$ (nc for no constant term).

To examine the properties of the ECM statistic under the null hypothesis of no cointegration, the data generation process is a standardized multivariate random walk for $x$ :

$$
\Delta x_{t} \sim I N\left(0, I_{k}\right)
$$

\subsection{Specifics of the Experimental Design}

The analysis focuses on the finite sample properties of the ECM statistic. Three "design parameters" are central to the statistic's distributional properties: the estimation sample size $(T)$, the total number of variables in $x_{t}(k)$, and the number of deterministic components in $D_{t}(d)$. To provide results for a wide range of situations common in empirical investigations, the simulations span a full factorial design of the following choices for $T, k$, and $D_{t}$ :

$$
\begin{aligned}
T & =(20,25,30,35,40,45,50,55,60,70,80,90,100,125,150,200,400,500,600,700,1000) \\
k & =(1,2,3,4,5,6,7,8,9,10,11,12) \\
D_{t} & =\left(\text { none; constant term; constant term, } t ; \text { constant term, } t, t^{2}\right)
\end{aligned}
$$

The values of $T$ include both large and small sample sizes, thereby aiming to provide information on both the test statistic's asymptotic properties and its finite sample deviations therefrom. The design includes all positive integer values of $k$ through 12 , sufficient for virtually all empirical applications. The choice of $D_{t}$ implies four test statistics: $\kappa_{n c}(k), \kappa_{c}(k), \kappa_{c t}(k)$, and $\kappa_{c t t}(k)$. Deterministic terms may be included in the model because they are required for adequate model specification: namely, the deterministic terms enter the data generation process. Also, a deterministic term of one order higher than "required" may be included in the model in order to obtain (asymptotic) similarity to the coefficients of the lower order deterministic terms; 
see Kiviet and Phillips (1992), Johansen (1994), and Nielsen and Rahbek (1998). Throughout, the model's lag length is set to unity $(\ell=1)$.

One minor modification exists for the experimental design in (31). Because $2 k-1+d$ degrees of freedom are used in the estimation of $(29)$, some smaller values of $T$ are not considered for larger values of $k$ that imply $2 k-1+d$ close to or exceeding $T$. Specifically, $T=20$ is dropped for $k=8 ; T=(20,25)$ are dropped for $k=(9,10)$; and $T=(20,25,30)$ are dropped for $k=(11,12)$.

\subsection{Monte Carlo Simulation}

This paper aims to provide numerically accurate estimates of the ECM statistic's distribution, particularly in its tails, where inference is commonly of concern. Thus, a large number of replications are simulated for each experiment in (31): specifically, 10 million replications for each pair of $T$ and $k$. Such large numbers of replications do not pose difficulties for calculations of sample moments, but they are problematic for calculating quantiles - and hence cumulative distribution functions - because the full set of replications must be stored and sorted. As a reasonably efficient secondbest alternative, the adopted design divides each experiment into 50 sets of 200,000 replications apiece, determines the quantiles for each set, and then averages the estimated quantile values across the sets. Partitioning each experiment into several sets also provides an easy way to measure experimental randomness. To estimate accurately the complete densities and cumulative distributions of the ECM statistic, a large number of quantiles are calculated: 221 in total, corresponding to $p=0.0001$, $0.0002,0.0005,0.001,0.002,0.003, \ldots, 0.008,0.009,0.010,0.015,0.020,0.025, \ldots$, $0.495,0.500,0.505, \ldots, 0.975,0.980,0.985,0.990,0.991,0.992, \ldots, 0.997,0.998$, 0.999, 0.9995, 0.9998, 0.9999, where $p$ denotes the quantile's percent level.

Because so many random numbers were generated, it was vital to use a pseudorandom number generator with a very long period. The generator used is that in MacKinnon $(1994,1996)$, which combines two different pseudo-random number generators recommended by L'Ecuyer (1988). The two generators were started with different seeds and allowed to run independently, so that two independent uniform pseudo-random numbers were generated at once. Each pair was then transformed into two $N(0,1)$ variates using the modified polar method of Marsaglia and Bray (1964, p. 260). See MacKinnon (1994, p. 170) for details.

\subsection{Post-simulation Analysis}

These Monte Carlo simulations generate a vast quantity of information: 221 estimated quantiles on 50 sets of replications for (typically) 21 sample sizes with 12 different values of $k$ and four choices of $D_{t}$ : over ten million numbers. Graphs and regressions provide two succinct ways of conveying and summarizing such information. This pa- 
per uses both means: graphs of asymptotic and finite sample cumulative distributions and densities, and response surfaces for finite sample critical values. An explanation is helpful for interpreting both the response surfaces and the graphs.

Typically, authors have tabulated estimated critical values for several sample sizes or for one large ("close to asymptotic") sample size. Such tabulations recognize the dependence of the critical values on the estimation sample size. That dependence can be approximated by regression, regressing the Monte Carlo estimates of the critical value on functions of the sample size. Such regressions are response surfaces: see Hammersley and Handscomb (1964) and Hendry (1984) for general discussions.

Here, for each triplet defined by the quantile's percent level $p$, the number of variables $k$, and the choice of deterministic components $D_{t}$, a response surface of the following form was estimated:

$$
q\left(T_{i}\right)=\theta_{\infty}+\theta_{1}\left(T_{i}^{a}\right)^{-1}+\theta_{2}\left(T_{i}^{a}\right)^{-2}+\theta_{3}\left(T_{i}^{a}\right)^{-3}+u_{i}
$$

The dependent variable $q\left(T_{i}\right)$ is the estimated finite sample $p$ th quantile from the Monte Carlo simulation with the $i$ th sample size $T_{i}$, which takes the values for $T$ in the experimental design (31). The regressors are an intercept and three inverse powers of the adjusted sample size $T_{i}^{a}\left(=T_{i}-(2 k-1)-d\right) ; \theta_{\infty}, \theta_{1}, \theta_{2}$, and $\theta_{3}$ are the corresponding coefficients; and $u_{i}$ is an error that reflects both simulation uncertainty and the approximation of the quantile's true functional form by the cubic in (32).

The benefits of these response surfaces are several. First, they reduce consumption costs to the user by summarizing numerous Monte Carlo experiments in a simple regression. Second, and relatedly, the coefficient $\theta_{\infty}$ is interpretable as the asymptotic $(T=\infty) p$ th quantile for the choice of $k$ and $D_{t}$ concerned. Estimation of that asymptotic quantile does not necessarily require very large sample sizes in the experimental design. Third, response surfaces reduce the Monte Carlo uncertainty by averaging (through regression) across different experiments. Fourth, response surfaces reduce the specificity of the simulations by allowing easy calculation of quantiles for sample sizes not included in the experimental design (31). Fifth, $p$-values and critical values at any level can be calculated from the response surfaces, as by the computer program accompanying MacKinnon (1996) for the Engle-Granger statistic $\tau_{d}(k)$ and by the one accompanying this paper for the ECM statistic $\kappa_{d}(k)$. Finally, and relatedly, response surfaces for commonly used quantiles (e.g., $p=5 \%$ ) are easily programmed into econometrics computer packages so as to provide empirical modelers with estimated finite sample critical values directly. For instance, response surfaces in MacKinnon (1991) for the Dickey-Fuller critical values appear in PcGive; see Hendry and Doornik (1996, p. 212).

Having estimated response surfaces of the form (32) for all experiments, it is relatively easy to plot estimated asymptotic distribution functions of the ECM statistic from the estimated values of $\theta_{\infty}$. Section 4.1 does so for both densities and cumulative distribution functions. Finite sample densities and distributions may be constructed 
from the Monte Carlo simulations directly, or from evaluation of (32) at finite sam-

ple sizes. Details of the numerical procedures for constructing the graphs appear in MacKinnon (1994, 1996).

While the response surfaces of the form (32) are convenient for constructing graphs of the asymptotic distributions, there are too many response surfaces to report them all: 10,608 response surfaces in total, i.e., $221 \times 4 \times 12$. For testing cointegration, however, response surfaces at common levels of significance are of particular interest, so Section 4.2 reports response surfaces for 1\%, 5\%, and 10\% levels. These response surfaces parallel those in MacKinnon (1991) for the Engle-Granger test statistic $\tau_{d}(k)$.

\section{Monte Carlo Results}

This section graphs estimated cumulative distribution functions and densities for the ECM statistic (Section 4.1) and reports selected response surfaces for that statistic (Section 4.2). Section 4.3 then examines critical values for the ECM statistic that were previously estimated in the literature and shows that the response surfaces in Section 4.2 encompass and supercede much of that work.

\subsection{Cumulative Distribution Functions and Densities}

Figures 1-4 plot the asymptotic cumulative distribution functions (CDFs) for the ECM statistics $\kappa_{n c}(k), \kappa_{c}(k), \kappa_{c t}(k)$, and $\kappa_{c t t}(k)$ respectively. Each figure graphs the CDFs for $k=1, \ldots 12$, along with the CDF for $N(0,1)$. Because the ECM statistic for $k=1$ is the Dickey-Fuller statistic, that special case is labeled explicitly on the graphs as $\tau_{d}(1)$.

Several features are notable in Figures 1-4. First, the cumulative distribution shifts systematically in the negative direction as the number of variables $k$ increases. The shift is numerically relatively constant, about -0.2 for an incremental increase in $k$, although the shift appears to be gradually declining in magnitude as $k$ increases. Second, comparing CDFs across figures, the magnitude of the shift appears to decline as the number of deterministic components increases. Third, even for $k=2$, the discrepancy between the CDF of $N(0,1)$ and that of the ECM statistic is considerable and increases as the number of deterministic components increases. Thus, inferences about cointegration when using the ECM statistic would be hazardous if (e.g.) a standardized normal distribution were assumed.

Figures 5-8 plot the corresponding asymptotic densities, which demonstrate those distributional shifts as well. Additionally, the densities highlight the unique shape of the distribution of the Dickey-Fuller statistic. Figure 5 in particular brings out the asymmetry in the density of the Dickey-Fuller statistic $\tau_{n c}(1)$, a feature apparent in MacKinnon (1994, Figure 3) and also noted by Abadir (1995), both analytically and 
in his Figure 1.

As discussed in Section 2, comparisons of the ECM and Engle-Granger (EG) procedures are of considerable interest. MacKinnon $(1994,1996)$ numerically estimated the distributions for the Dickey-Fuller statistic applied to the Engle-Granger cointegration residuals. In the current Monte Carlo simulations, those distributions were estimated, based on the pseudo-random numbers used for estimating the distributions of the ECM statistic. Figures 9-12 plot the asymptotic CDFs of the ECM and EngleGranger statistics for $k=2$ and $k=12$. For all choices of deterministic components, the CDF of the Engle-Granger statistic $\tau_{d}(k)$ is shifted to the left of that for $\kappa_{d}(k)$, substantially so for larger values of $k$.

Figures 13-16 plot the corresponding asymptotic densities, which make the nature of the shifts more apparent. The density of $\tau_{d}(2)$ is shifted by only a few tenths relative to $\kappa_{d}(2)$, whereas that for $\tau_{d}(12)$ is often shifted by one to two units relative to $\kappa_{d}(12)$. Figures 13-16 also show that the distribution of the ECM statistic $\kappa_{d}(k)$ is relatively close to normality with unit variance, whereas the distribution of $\tau_{d}(k)$ is not.

Figures 1-16 all concern asymptotic properties. While asymptotic properties are essential for understanding the nature of the ECM statistic, empirical sample sizes are often small, so it is valuable to assess the discrepancies between asymptotic and finite sample distributions. Figures 17 and 18 plot asymptotic and finite sample densities for $\kappa_{d}(2)$ and $\kappa_{d}(12)$, where "finite sample" is $T=20$ for $\kappa_{d}(2)$ and $T=50$ for $\kappa_{d}(12)$. For all choices of deterministic components, the asymptotic densities tend to be more peaked than the finite sample ones, perhaps reflecting the contribution of estimation uncertainty to the latter. While the finite sample densities tend to shift to the left as the sample size increases, this does not hold uniformly for all parts of the density. Shifts to the right are particularly noticeable in the left tails in Figure 17. Figures 17 and 18 each include the densities for all four possibilities of deterministic components for a given ECM statistic. Each additional deterministic component systematically shifts the statistic's density to the left, and the incremental shift is almost invariant to the total number of deterministic components.

\subsection{Response Surfaces for Critical Values}

As just discussed, the distribution of the ECM statistic $\kappa_{d}(k)$ depends systematically on the number of variables $k$, the number of deterministic components $d$, and the sample size $T$. The current subsection quantifies these dependencies through response surfaces for three quantiles: those at $1 \%, 5 \%$, and $10 \%$.

To motivate these dependencies, consider Figure 19, which plots the data to be analyzed in the response surfaces. Specifically, each 3D graph in Figure 19 plots the within-experiment average for the estimated quantile against $k$ and $\left(T^{a} / 100\right)^{-1}$ (a rescaled inverse of the adjusted sample size), given the choice of $d$ and the quantile's percent level $p$. The previously noted dependencies on $d, k, T$, and $p$ are all apparent 
in Figure 19. Additionally, $T$ appears to have relatively little affect on the $5 \%$ and $10 \%$ quantiles.

Tables $2-5$ list the least squares estimates of the response surface coefficients $\theta_{\infty}, \theta_{1}, \theta_{2}$, and $\theta_{3}$ for the $1 \%, 5 \%$, and $10 \%$ quantiles with $k=1, \ldots 12 .{ }^{4}$ The conditional ECM is estimated with no deterministic terms (Table 2), with a constant term only (Table 3), with a constant term and a linear trend only (Table 4), and with a constant term, a linear trend, and a quadratic trend (Table 5). The tables also include the estimated standard error ("s.e.") for $\theta_{\infty}$ to provide a measure of uncertainty for the estimated asymptotic quantile. This standard error is always smaller than 0.001, assuring high precision in the estimates. The estimated standard errors are jackknife heteroskedasticity consistent standard errors from MacKinnon and White (1985), as the experimental design may induce some heteroskedasticity in the estimated quantiles across different sample sizes.

The tables report an additional measure of uncertainty: $\hat{\sigma}$, the estimated equation standard error from the response surface (32). The estimate $\hat{\sigma}$ reflects both the simulation uncertainty from estimating the quantile $q\left(T_{i}\right)$ rather than knowing it and the approximation error from using the cubic form in (32) rather than the true functional form. The experimental design also permits estimating the simulation uncertainty alone and so evaluating the statistical adequacy of the response surface. Specifically, the design implies 50 independent estimates of the quantile $q\left(T_{i}\right)$; see Section 3.3. A given response surface regression includes 50 values for $q\left(T_{i}\right)$ across all values of the sample size, entailing (e.g.) 1050 "observations" (50 values $\times 21$ sample sizes) in the response surface for $\kappa_{c t}(2)$ at the $1 \%$ level. Thus, an average of the pure simulation uncertainty in a given response surface may be estimated by the equation standard error from a regression of $q\left(T_{i}\right)$ on a set of (e.g.) 21 dummies, one for each sample size. The response surface (32) is nested within this more general regression, and comparison of the two equations generates an $F$-statistic for formally testing the statistical significance of the error in approximating the response function's functional form; see Ericsson (1991). In spite of the large number of replications, this test rejects at the $5 \%$ level for only 7 of the 144 response surfaces $(4.86 \%)$. No rejection increases $\hat{\sigma}$ by more than $1.1 \%$. Thus, a cubic in the inverse of the adjusted sample size appears statistically and numerically adequate to approximate the simulated finite sample behavior at the $1 \%, 5 \%$, and $10 \%$ quantiles for this experimental design.

As they stand, Tables $2-5$ provide a valuable tool for judging whether or not cointegration is present in empirical conditional ECMs. Econometric software packages could easily generate finite sample critical values for users from Tables 2-5. Even without direct incorporation into such packages, calculation of critical values is trivially easy from the tables. For instance, for a conditional four-variable $(k=4)$ ECM

\footnotetext{
${ }^{4}$ The response surfaces reported in Tables $2-5$ differ slightly from those underlying Figures $1-$ 18. The former are estimated by OLS, whereas the latter are estimated by GMM, using methods discussed in MacKinnon (1996). The two approaches yield numerically very similar results.
} 
with a constant term estimated on 47 observations, the finite sample critical value at the $5 \%$ level is -3.84 , i.e., $-3.7592-(2.92 / 39)-\left(3.7 / 39^{2}\right)+\left(5 . / 39^{3}\right)$ from Table 3 , noting that $T^{a}=47-7-1=39$.

As with Figures 1-19, Tables 2-5 show the systematic and regular dependence of the properties of the ECM statistic on the number of variables $k$ and the number of deterministic components $d$. This dependence leads to a simple rule of thumb that is captured in the following OLS "meta" response surface for the asymptotic 1\%, $5 \%$, and $10 \%$ quantiles $\theta_{\infty}$ reported in Tables $2-5$ :

$$
\begin{aligned}
& \theta_{\infty}=-\underset{(0.03)}{2.98}-\underset{(0.003)}{0.187 k}-\underset{(0.01)}{0.33(d-1)}+\left\{\begin{array}{c}
-0.60 \\
(0.02) \\
0 \\
0.32 \\
+0.32 \\
(0.02)
\end{array} \text { at the } 5 \% \text { level } 10 \%\right. \text { level } \\
& R^{2}=0.987 \quad \hat{\sigma}=0.109 \text { number of "observations" }=132,
\end{aligned}
$$

where $R^{2}$ is the squared multiple correlation coefficient, and $\hat{\sigma}$ is the standard deviation of the residuals. Values of $\theta_{\infty}$ for $k=1$ (the Dickey-Fuller statistic) are excluded in (33), as only $k>1$ is of interest for testing cointegration. From (33), a crude approximation $\theta_{\text {crude }}$ to the (lower) $5 \%$ critical value for the ECM statistic is:

$$
\theta_{\text {crude }}=-3.0-0.2 k-0.3(d-1)
$$

The negative coefficients in (34) can be easily remembered as a " $3 / 2 / 3$ " rule of thumb: an intercept of -3.0 , a coefficient of -0.2 on the number of variables in $x$, and a coefficient of -0.3 on the number of deterministic terms over and above a constant term.

Figure 20 highlights this near-linear dependence of the asymptotic quantile $\theta_{\infty}$ on $k$ and $d$. Each 3D graph in Figure 20 plots $\theta_{\infty}$ against $k$ and $d$, given the quantile's percent level $p$. The surfaces are virtually planar except for the Dickey-Fuller statistic $(k=1)$, which is excluded from (33) and (34).

Equations (33) and (34) quantify the straightforward dependencies of the ECM statistic's quantiles on $k$ and $d$, they provide a mechanism for extrapolating critical values for values of $k$ and $d$ outside the experimental design (31), and they offer a rough-and-ready way of assessing empirical results when Tables $2-5$ are not available. Preferably, though, Tables $2-5$ or the related computer program should be used.

\subsection{An Encompassing of Existing Monte Carlo Results}

Two previous studies - Banerjee, Dolado, Galbraith, and Hendry (1993) and Banerjee, Dolado, and Mestre (1998) — report estimated critical values for the ECM statistic with $k>1$. Dickey, as reported in Fuller (1976), generated critical values for $k=1$ 
(i.e., for the Dickey-Fuller statistic); and the response surfaces in MacKinnon (1991) for $\tau_{d}(k)$ include $\tau_{d}(1)$. This subsection shows that these previous results for the $1 \%$, $5 \%$, and $10 \%$ levels are subsumed and superceded by the response surfaces reported in Tables $2-5$.

This encompassing of pre-existing Monte Carlo studies is achieved by evaluating the response surfaces in Tables $2-5$ over the experimental designs of those past studies and comparing the critical values derived from Tables $2-5$ with those reported in the studies' simulations. Deviations between the two types of critical values typically are small relative to the estimated simulation uncertainty of the pre-existing Monte Carlo studies or are simply small numerically. Hence, Tables $2-5$ encompass those studies. For this purpose, the simulation uncertainty associated with the response surfaces in Tables $2-5$ is treated as negligible. That assumption seems reasonable. The largest value of $\hat{\sigma}$ in Tables $2-5$ is under 0.02 , and each $(T, d, k, p)$ quadruplet includes 50 estimates of the quantile, implying an associated standard error of the response surface quantile of under 0.003. Frequently, that standard error is under 0.001. The remainder of this subsection briefly describes the Monte Carlo simulations in each study and the outcomes of the encompassing exercise.

Banerjee, Dolado, Galbraith, and Hendry (1993, Table 7.6, p. 233) report estimated critical values at the $1 \%, 5 \%$, and $10 \%$ levels for $\kappa_{c}(2)$ at $T=(25,50,100)$, using 5000 replications per experiment. Deviations relative to the response surfaces from Table 3 are all under 0.1 in absolute value. Using the values of $\hat{\sigma}$ in Table 3 as a benchmark and rescaling by the square root of the ratio of simulations calculated, the estimated standard errors for the three quantiles in Banerjee, Dolado, Galbraith, and Hendry (1993) are approximately 0.063, 0.032, and 0.025. Thus, the observed discrepancies between the estimated quantiles in Banerjee, Dolado, Galbraith, and Hendry (1993) and those calculated from Table 3 appear as expected, given the simulation uncertainty of the former.

Banerjee, Dolado, and Mestre (1998, Table I) report estimated critical values at the $1 \%, 5 \%, 10 \%$, and $25 \%$ levels for $\kappa_{c}(k)$ and $\kappa_{c t}(k)(k=2, \ldots, 6)$ at $T=$ $(25,50,100,500, \infty)$, using 25,000 replications per experiment. Deviations relative to the response surfaces from Tables 3 and 4 are all under 0.2 in absolute value, and are typically 0.04 or smaller in magnitude. ${ }^{5}$ The estimated standard errors for the $1 \%$, $5 \%$, and $10 \%$ quantiles in Banerjee, Dolado, and Mestre (1998) are approximately $0.028,0.014$, and 0.011 .

Fuller (1976, Table 8.5.2, p. 373) lists numerous quantiles for $\tau_{n c}(1), \tau_{c}(1)$, and $\tau_{c t}(1)$ at $T=(25,50,100,250,500, \infty)$. Standard errors for most estimates are reported to be less than 0.02 , and critical values are reported to two decimals. Deviations relative to the response surfaces from Tables $2-4$ are all under 0.015 in absolute value and are typically no more than 0.007 in magnitude, close to what would be

\footnotetext{
${ }^{5}$ Deviations for the $25 \%$ level were not calculated, as the $25 \%$ level was not included in Tables $2-5$.
} 
expected from pure rounding errors.

Inter alia, MacKinnon (1991, Table 1) reports response surfaces for $\tau_{n c}(1), \tau_{c}(1)$, and $\tau_{c t}(1)$. For the sample sizes simulated in his study and in the current paper, deviations between critical values calculated from his response surfaces and those in Tables 2-4 are all smaller than 0.02 in absolute value and are typically smaller than 0.003 in magnitude.

To summarize, the response surfaces in Tables $2-5$ for the $1 \%, 5 \%$, and $10 \%$ levels numerically encompass corresponding results from previous Monte Carlo studies in Fuller (1976), MacKinnon (1991), Banerjee, Dolado, Galbraith, and Hendry (1993), and Banerjee, Dolado, and Mestre (1998). Simulation uncertainty in those previous studies appears to be the dominant factor explaining discrepancies relative to the response surfaces in Tables $2-5$.

\section{Three Empirical Applications}

This section applies the finite sample critical values derived above and the computer program for calculating $p$-values to three empirical error correction models. Section 5.1 considers a model of U.K. narrow money demand from Hendry and Ericsson (1991), Section 5.2 a model of U.K. consumers' expenditure from Davidson, Hendry, Srba, and Yeo (1978), and Section 5.3 a model of U.S. federal government debt from Hamilton and Flavin (1986). The models in Davidson, Hendry, Srba, and Yeo (1978) and Hendry and Ericsson (1991) have played significant roles in the literature on ECMs and cointegration, and Hamilton and Flavin (1986) was one of the early papers to employ unit root statistics for testing economic hypotheses. Each subsection briefly reviews the estimated equation and considers corresponding conditional ECM tests. Tables summarize the results, reporting the empirical $t$-values for testing cointegration, along with corresponding critical values and $p$-values. Use of the critical values from Tables 2-5 for the ECM statistic affects the economic inferences drawn in the second two studies.

Several issues arise in testing for cointegration in these models. First, the ECMs for money demand and consumers' expenditure were each derived from unrestricted ADLs. Both the ADLs and the ECMs allow testing of cointegration, although these ECMs require slight modification to apply the critical values from Tables $2-5$. Second, dynamic specification affects the degrees of freedom used in estimation. Hence, when computing critical values, the adjusted sample size $T^{a}$ is calculated as $T-h$ (rather than as $T-(2 k+d-1)$ ), where $h$ is the total number of regressors, including deterministic variables. The calculation of $p$-values utilizes $h$ similarly. Third, the choice of deterministic variables affects the $t$-values and the corresponding critical values and $p$-values, so potentially affecting inference. Finally, omitted seasonality is important in the model of consumers' expenditure, as is nonlinearity of the determin- 
istic trend and lack of weak exogeneity in the model of government debt. Throughout this section, capital letters denote both the generic name and the level of a variable, logarithms are in lowercase, and OLS standard errors are in parentheses $(\cdot)$.

\subsection{U.K. Narrow Money Demand}

Hendry and Ericsson (1991, equation (6)) model U.K. narrow money demand as a conditional ECM, whose final parsimonious form is as follows.

$$
\begin{gathered}
\Delta(m-p)_{t}=-\underset{(0.13)}{0.69} \Delta p_{t}-\underset{(0.06)}{0.17} \Delta(m-p-i)_{t-1}-\underset{(0.060)}{0.630} R_{t}^{\text {net }} \\
-\begin{array}{c}
0.093 \\
(0.009)
\end{array}(m-p-i)_{t-1}+\underset{(0.004)}{0.023} \\
T=100[1964 Q 3-1989 Q 2] \quad R^{2}=0.76 \quad \hat{\sigma}=1.313 \%
\end{gathered}
$$

The data are nominal narrow money $M_{1}$ ( $M$, in $£$ millions), real total final expenditure (TFE) at 1985 prices $(I$, in $£$ millions), the TFE deflator $(P, 1985=1.00)$, and the net interest rate $\left(R^{n e t}\right.$, in percent per annum expressed as a fraction). The last series is the differential between the three-month local authority interest rate and a learning-adjusted retail sight-deposit interest rate.

While the $t$-value on error correction term $(m-p-i)_{t-1}$ in (35) is very large and negative $(-10.87)$, even asymptotic significance levels are not known, given the presence of nuisance parameters; see Kremers, Ericsson, and Dolado (1992) and Kiviet and Phillips (1992). This difficulty arises because one of the coefficients in the cointegrating vector - the long-run income elasticity — is constrained. One solution is to estimate that coefficient unrestrictedly, as occurs when estimating (35) with $i_{t-1}$ added.

$$
\begin{aligned}
& \Delta(m-p)_{t}=-\underset{(0.13)}{0.70} \Delta p_{t}-\underset{(0.06)}{0.18} \Delta(m-p-i)_{t-1}-\underset{(0.067)}{0.611} R_{t}^{\text {net }} \\
& -\underset{(0.011)}{0.088}(m-p-i)_{t-1}+\underset{(0.010)}{0.006} i_{t-1}-0.05 \\
& T=100[1964 Q 3-1989 Q 2] \quad R^{2}=0.76 \quad \hat{\sigma}=1.317 \%
\end{aligned}
$$

The $t$-value on $(m-p-i)_{t-1}$ in $(36)$ is -7.78 , which is significant at the $1 \%$ level for $\kappa_{c}(4)$, with critical value of -4.45 . In fact, the finite sample $p$-value for -7.78 is 0.0000 .

Equations (35) and (36) can be derived from an unrestricted fifth-order autoregressive distributed lag model in $m-p, \Delta p, i$, and $R^{\text {net }}$. The ECM statistic for that ADL is -5.17 , also significant at the $1 \%$ level for $\kappa_{c}(4)$, with critical value of -4.47 . Its finite sample $p$-value is 0.0014 , indicating a minor loss in power from estimating additional coefficients on dynamics relative to (36).

Both this fifth-order ADL and the ECM in (36) include one deterministic component: a constant term. Table 6 reports the statistic $\kappa_{d}(4)$ for the four choices of 
deterministic components considered in the sections above; the value of $h$; the finite sample, asymptotic, and crude critical values at the 1\%,5\%, and $10 \%$ levels; finite sample and asymptotic $p$-values; the estimated equation standard error $\hat{\sigma}$; and an $F$-statistic for testing the significance of omitted deterministic components. The symbols ${ }^{+},{ }^{*}$, and ${ }^{* *}$ denote rejection at the $10 \%, 5 \%$, and $1 \%$ levels respectively. With a constant term, linear trend, and quadratic trend included, the statistic $\kappa_{c t t}(4)$ is insignificant at the $10 \%$ level for both the ADL and the ECM: their $p$-values are 0.3859 and 0.4544 . With fewer deterministic components, cointegration is detected at the $0.5 \%$ level or smaller in the ADL and the ECM, as the statistics $\kappa_{c t}(4), \kappa_{c}(4)$, and $\kappa_{n c}(4)$ show.

The final column in Table 6 lists the $F$-statistics for testing the significance of the omitted deterministic components in the corresponding regressions, relative to the regressions for obtaining $\kappa_{c t t}(4)$ : degrees of freedom for the $F$-statistics appear in parentheses as $F(\cdot, \cdot)$, and the statistics' $p$-values are in brackets $[\cdot]$. These $F$-statistics indicate that the constant term, linear trend, and quadratic trend are statistically insignificant, so all the reported ECM statistics in Table 6 make statistically justifiable assumptions about these deterministic components. The statistics $\kappa_{n c}(4), \kappa_{c}(4)$, and $\kappa_{c t}(4)$ reject at standard levels, but $\kappa_{c t t}(4)$ does not, pointing to the value of parsimony in deterministic components for obtaining increased power of the cointegration test, when parsimony is merited. The insignificance of a linear trend is particularly interesting. In a system analysis of this dataset, Hendry and Mizon (1993) find a second cointegrating vector, which includes a linear trend; but in their system model, that cointegrating vector does not enter the equation for money.

Table 6 lists the asymptotic and crude critical values at the 1\%, 5\%, and $10 \%$ levels, and these differ by 0.21 at most from the calculated finite sample critical values. Likewise, the finite sample and asymptotic $p$-values in the table differ by only modest amounts. These numerically small discrepancies are not surprising because the sample size is relatively large $(T=100)$.

\subsection{U.K. Consumers' Expenditure}

Davidson, Hendry, Srba, and Yeo (1978, equation (45)**) model U.K. consumers' expenditure on nondurables and services, obtaining the following parsimonious ECM.

$$
\begin{gathered}
\Delta_{4} c_{t}=\begin{array}{c}
0.48 \\
(0.03)
\end{array} \Delta_{4} i_{t}-\begin{array}{c}
0.23 \\
(0.04)
\end{array} \Delta_{1} \Delta_{4} i_{t}-\underset{0.09}{(0.01)}(c-i)_{t-4} \\
+\underset{(0.006}{0.002)} \Delta_{4} D_{t}^{*}-\begin{array}{c}
0.12 \\
(0.02)
\end{array} \Delta_{4} p_{t}-\begin{array}{c}
0.31 \\
(0.10)
\end{array} \Delta_{1} \Delta_{4} p_{t} \\
T=71[1958 Q 2-1975 Q 4] \quad R^{2}=0.96 \quad \hat{\sigma}=0.601 \%
\end{gathered}
$$

The data are U.K. consumers' expenditure on nondurables and services $(C$, in £ millions, 1970 prices), U.K. personal disposable income ( $I$, in $£$ millions, 1970 prices), 
the implicit deflator for $C(P, 1970=1.00)$, and a dummy variable for certain tax effects $\left(D^{*}\right)$. The $t$-value on $(c-i)_{t-4}$ in $(37)$ is -8.10 , but, as with (35), the critical values in Tables $2-5$ are not directly applicable. Adding $i_{t-4}$ to (37) solves this problem.

$$
\begin{aligned}
& \Delta_{4} c_{t}=\underset{(0.03)}{0.46} \Delta_{4} i_{t}-\underset{(0.04)}{0.22} \Delta_{1} \Delta_{4} i_{t}-\underset{(0.024)}{0.055}(c-i)_{t-4}+\underset{(0.0004)}{0.0007} i_{t-4} \\
& +\underset{(0.002)}{0.006} \Delta_{4} D_{t}^{*}-\underset{(0.02)}{0.11} \Delta_{4} p_{t}-\underset{(0.10)}{0.27} \Delta_{1} \Delta_{4} p_{t} \\
& T=71[1958 Q 2-1975 Q 4] \quad R^{2}=0.96 \quad \hat{\sigma}=0.591 \%
\end{aligned}
$$

The $t$-value on $(c-i)_{t-4}$ in $(38)$ is -2.31 , which is not significant at even the $10 \%$ level for $\kappa_{n c}(3)$ : its $p$-value is 0.1845 .

Equation (37) was derived from an unrestricted ADL in $c, i$, and $\Delta p{ }^{6}$ Table 7 reports the $t$-values for both the ADL and the ECM (38) with various choices of deterministic components. None of the $t$-values is significant, ostensibly casting doubt on the interpretation of (37) in Davidson, Hendry, Srba, and Yeo (1978). Alternatively, this evidence may indicate the considerable statistical value of imposing long-run restrictions that are in fact correct; see Horvath and Watson (1995).

Another explanation for these negative results turns on model mis-specification. First, (37) contains hidden seasonality: quarterly dummies are statistically significant when added to (37). Table 7 reports an additional set of $t$-values derived from models including quarterly dummy variables (labeled with " $+Q_{i}$ "). These ECM statistics present modest evidence in favor of cointegration, with $\kappa_{c t}(3), \kappa_{c}(3)$, and $\kappa_{n c}(3)$ (but not $\left.\kappa_{c t t}(3)\right)$ all rejecting at the $10 \%$ level. That said, the $F$-statistics for the deterministic components are sometimes significant. Second, an additional variable (liquidity) may be required to obtain cointegration; see Hendry and von Ungern-Sternberg (1981).

\subsection{U.S. Federal Government Debt}

The third model is an ADL from Hamilton and Flavin (1986, p. 816), relating real U.S. federal government debt to a deterministic nonlinear trend or "bubble" $(1+r)^{t}$ and the budget surplus.

$$
\begin{gathered}
B_{t}=\begin{array}{c}
48.41 \\
(26.40)
\end{array}-\underset{(21.29)}{22.68}(1+r)^{t}+\underset{(0.21)}{0.69} B_{t-1}+\underset{(0.24)}{0.20} B_{t-2} \\
-\begin{array}{c}
1.30 \\
(0.13)
\end{array} S_{t}-0.63 \quad S_{t-1} \\
T=23[1962-1984] \quad R^{2}=0.98 \quad \hat{\sigma}=7.405
\end{gathered}
$$

\footnotetext{
${ }^{6}$ The ADLs in Table 7 include five lags of $c$ and $i$, but four lags of $\Delta p$, with the latter corresponding to five lags of $p$ in Davidson, Hendry, Srba, and Yeo (1978, Table 3). The ADLs in Table 7 use $\Delta p$ rather than $p$, as $\Delta p$ itself behaves like an $\mathrm{I}(1)$ variable.
} 
The data are the adjusted debt $(B)$ for the end of the fiscal year and the adjusted surplus $(S)$ for the fiscal year (both in $\$$ millions, 1967 prices). The variable $r$ is set to 0.0112 , the average ex post real interest rate on U.S. government bonds over 1960-1984. The coefficient on $(1+r)^{t}$ is statistically insignificant, consistent with the absence of a speculative bubble. From this and related evidence, Hamilton and Flavin (1986, pp. 816-817) conclude that “. . . the data appear quite consistent with the assertion that the government has historically operated subject to the constraint that expenditures not exceed receipts in expected present-value terms."

This interpretation of the evidence assumes a long-run solution to (39) relating debt and surplus. That is equivalent to assuming both cointegration between $B$ and $S$, and the presence of the corresponding cointegrating vector in (39). Empirically, however, (39) does not support cointegration of $B$ and $S$. Rewriting (39) as an unrestricted ECM obtains the following equation.

$$
\begin{aligned}
& \Delta B_{t}=\underset{(26.40)}{48.41}-\underset{(21.29)}{22.68}(1+r)^{t}-\underset{(0.08)}{0.10} B_{t-1}-\underset{(0.24)}{0.20} \Delta B_{t-1} \\
& -\underset{(0.13)}{1.30} \Delta S_{t}-\underset{(0.36)}{1.92} S_{t-1} \\
& T=23[1962-1984] \quad R^{2}=0.94 \quad \hat{\sigma}=7.405
\end{aligned}
$$

The $t$-value on $B_{t-1}$ is -1.36 , which is insignificant at the $10 \%$ level for $\kappa_{c t}(2)$, with critical value of -3.53 . Using the critical value for $\kappa_{c t}(2)$ assumes that $(1+r)^{t}$ is well approximated by a linear trend, which, visually, it is. Alternatively, the $10 \%$ critical value for $\kappa_{c t t}(2)$ is -3.95 , again with no rejection. The finite sample $p$-values under these two alternative assumptions are 0.8386 and 0.9247 . Notably, estimating (40) (or $(39))$ with $t$ and $t^{2}$ rather than with $(1+r)^{t}$ obtains a statistically significantly better-fitting model, pointing to mis-specification in (40).

Table 8 reports the $t$-values and critical values for (40) with various choices of deterministic components. The bubble $(1+r)^{t}$ is statistically insignificant in (40), whereas a linear trend and quadratic trend in its stead are statistically significant. Even so, the resulting $t$-value for $\kappa_{c t t}(2)$ is -2.96 , which is insignificant at the $10 \%$ level, having a $p$-value of 0.3688 . Cointegration does not appear to hold in this conditional model, undercutting the economic inferences drawn by Hamilton and Flavin (1986).

The sample size in (40) is the smallest of the three models examined. Correspondingly, the finite sample adjustments for critical values are typically larger numerically in Table 8 than in Tables 6 and 7 , with the largest adjustment being -0.72 at the $1 \%$ level, i.e., about two thirds of a standard error in the $t$-value. The $p$-values have small finite sample adjustments, which mainly reflect each reported $t$-value being far from the lower tail of the associated density; cf. Figure 17.

The single-equation results in Table 8 all assume that $S$ is weakly exogenous, whereas $S$ does not appear to be so empirically. Starting with a second-order vector 
autoregression in $B$ and $S$, a single cointegrating vector is apparent from the Johansen procedure when $(1+r)^{t}$ or a linear trend is restricted to lie in the cointegration space. Weak exogeneity of $S$ is rejected, as is that of $B$, invalidating cointegration analysis in a conditional single equation such as (39). Without weak exogeneity, single equation inference about cointegration is hazardous at best; and testing the implied exogeneity assumptions is clearly important. For example, in the Johansen procedure, the coefficient on the bubble $(1+r)^{t}$ or on the linear trend is statistically significant and negatively related to $B$, whichever type of trend is included. That contrasts with the statistical insignificance of the coefficient on $(1+r)^{t}$ in (39). Furthermore, the negative coefficient on the trend is economically surprising and puzzling, although it may be indicative of certain non-ergodic features of the data: see Kremers (1988) inter alia.

In summary, the first two empirical analyses illustrate the importance of parsimony, both in the choice of deterministic terms and in the reduction from an ADL to a simpler ECM. Mis-specification can render inference hazardous, whether the misspecification is direct (as with the omitted quarterly dummies) or indirect (as with an assumption of weak exogeneity). Imposition of valid restrictions on the cointegrating vector may increase power, although asymptotically correct critical values for such ECM statistics have been derived only for the case when all cointegrating coefficients are known; see Hansen (1995, Table 1).

\section{Conclusions}

This paper has assessed the distributional properties of the ECM statistic for testing cointegration. Graphs and response surfaces provide complementary summaries of the vast array of results from the Monte Carlo study undertaken. Both the graphs and the response surfaces highlight some simple dependencies of the quantiles on the number of variables in the ECM, the choice of deterministic components, and the estimation sample size. The reported response surfaces provide a computationally convenient way for calculating finite sample critical values at the $1 \%, 5 \%$, and $10 \%$ levels. The response surfaces also encompass and supercede much of the literature's previous estimates of critical values for the ECM statistic. A computer program, freely available over the Internet, can be used to calculate $p$-values and critical values at any level. Empirical conditional ECMs are ubiquitous in the cointegration literature, so these tools should be of immediate use to the empirical modeler. Three previous empirical studies illustrate how critical values and $p$-values for the ECM statistic can be employed in practice, and how their use may affect economic inferences.

Several limitations of the current study come to mind, thereby suggesting some possible extensions. First, the model's lag order is assumed to be (and is) unity throughout the Monte Carlo analysis. For longer lags, the adjusted sample size may 
be corrected for additional degrees of freedom lost in estimation and thence used to calculate critical values from a response surface, as in Section 5. This refinement may not be sufficient in itself, so an extended analysis, such as in Cheung and Lai (1995) for the Dickey-Fuller statistic, may be required. Second, all of the ECM statistics with deterministic components have those components fully unconstrained in estimation. In analyzing a similar statistic, Harbo, Johansen, Nielsen, and Rahbek (1998) and Doornik, Hendry, and Nielsen (1998) argue strongly for constraining the highest-order deterministic component to lie in the cointegration space, so distributional properties for so constrained versions of $\kappa_{c}(k), \kappa_{c t}(k)$, and $\kappa_{c t t}(k)$ are of interest. That said, virtually all empirically calculated ECM statistics to date have been with unconstrained deterministic components. Finally, the current paper has considered the properties of the ECM statistic only under the null of no cointegration. While Banerjee, Dolado, Galbraith, and Hendry (1993), Campos, Ericsson, and Hendry (1996), and Banerjee, Dolado, and Mestre (1998) present some calculations on the power of the ECM statistic, further analysis could be illuminating, particularly comparisons with the Johansen procedure and the Engle-Granger procedure under various assumptions about weak exogeneity and common factor restrictions.

\section{References}

Abadir, K. M. (1995) "The Limiting Distribution of the $t$ Ratio Under a Unit Root", Econometric Theory, 11, 4, 775-793.

Banerjee, A., J. J. Dolado, J. W. Galbraith, and D. F. Hendry (1993) Co-integration, Error Correction, and the Econometric Analysis of Non-stationary Data, Oxford University Press, Oxford, England.

Banerjee, A., J. J. Dolado, and R. Mestre (1998) "Error-correction Mechanism Tests for Cointegration in a Single-equation Framework", Journal of Time Series Analysis, 19, $3,267-283$.

Campos, J., N. R. Ericsson, and D. F. Hendry (1996) "Cointegration Tests in the Presence of Structural Breaks", Journal of Econometrics, 70, 1, 187-220.

Cheung, Y.-W., and K. S. Lai (1995) "Lag Order and Critical Values of the Augmented Dickey-Fuller Test", Journal of Business and Economic Statistics, 13, 3, 277-280.

Davidson, J. E. H., D. F. Hendry, F. Srba, and S. Yeo (1978) "Econometric Modelling of the Aggregate Time-series Relationship Between Consumers' Expenditure and Income in the United Kingdom", Economic Journal, 88, 352, 661-692.

Dickey, D. A., and W. A. Fuller (1979) "Distribution of the Estimators for Autoregressive Time Series with a Unit Root", Journal of the American Statistical Association, 74, $366,427-431$.

Dickey, D. A., and W. A. Fuller (1981) "Likelihood Ratio Statistics for Autoregressive Time Series with a Unit Root", Econometrica, 49, 4, 1057-1072. 
Doornik, J. A. (1998) "Approximations to the Asymptotic Distributions of Cointegration Tests", Journal of Economic Surveys, 12, 5, 573-593.

Doornik, J. A. (1999) "Erratum [Approximations to the Asymptotic Distributions of Cointegration Tests]", Journal of Economic Surveys, 13, 2, i.

Doornik, J. A., and D. F. Hendry (1996) PcGive Professional 9.0 for Windows, International Thomson Business Press, London.

Doornik, J. A., D. F. Hendry, and B. Nielsen (1998) "Inference in Cointegrating Models: UK M1 Revisited", Journal of Economic Surveys, 12, 5, 533-572.

Elliott, G. (1995) "Tests for the Correct Specification of Cointegrating Vectors and the Error Correction Model", mimeo, Department of Economics, University of California at San Diego, La Jolla, California, December.

Engle, R. F., and C. W. J. Granger (1987) "Co-integration and Error Correction: Representation, Estimation, and Testing", Econometrica, 55, 2, 251-276.

Ericsson, N. R. (1991) "Monte Carlo Methodology and the Finite Sample Properties of Instrumental Variables Statistics for Testing Nested and Non-nested Hypotheses", Econometrica, 59, 5, 1249-1277.

Fuller, W. A. (1976) Introduction to Statistical Time Series, John Wiley and Sons, New York.

Hamilton, J. D., and M. A. Flavin (1986) "On the Limitations of Government Borrowing: A Framework for Empirical Testing", American Economic Review, 76, 4, 808-819.

Hammersley, J. M., and D. C. Handscomb (1964) Monte Carlo Methods, Chapman and Hall, London.

Hansen, B. E. (1995) "Rethinking the Univariate Approach to Unit Root Testing: Using Covariates to Increase Power", Econometric Theory, 11, 5, 1148-1171.

Harbo, I., S. Johansen, B. Nielsen, and A. Rahbek (1998) "Asymptotic Inference on Cointegrating Rank in Partial Systems", Journal of Business and Economic Statistics, 16, 4, 388-399.

Hendry, D. F. (1984) "Monte Carlo Experimentation in Econometrics", Chapter 16 in Z. Griliches and M. D. Intriligator (eds.) Handbook of Econometrics, Volume 2, NorthHolland, Amsterdam, 937-976.

Hendry, D. F. (1989) PC-GIVE: An Interactive Econometric Modelling System, Version 6.0/6.01, Institute of Economics and Statistics and Nuffield College, University of Oxford, Oxford, England.

Hendry, D. F. (1995a) Dynamic Econometrics, Oxford University Press, Oxford, England.

Hendry, D. F. (1995b) "On the Interactions of Unit Roots and Exogeneity", Econometric Reviews, 14, 4, 383-419.

Hendry, D. F., and J. A. Doornik (1996) Empirical Econometric Modelling Using PcGive 9.0 for Windows, International Thomson Business Press, London.

Hendry, D. F., and N. R. Ericsson (1991) "Modeling the Demand for Narrow Money in the United Kingdom and the United States", European Economic Review, 35, 4, 833-881 (with discussion). 
Hendry, D. F., and G. E. Mizon (1993) "Evaluating Dynamic Econometric Models by Encompassing the VAR", Chapter 18 in P. C. B. Phillips (ed.) Models, Methods, and Applications of Econometrics: Essays in Honor of A. R. Bergstrom, Blackwell Publishers, Cambridge, Massachusetts, 272-300.

Hendry, D. F., A. Pagan, and J. D. Sargan (1984) "Dynamic Specification", Chapter 18 in Z. Griliches and M. D. Intriligator (eds.) Handbook of Econometrics, Volume 2, NorthHolland, Amsterdam, 1023-1100.

Hendry, D. F., and T. von Ungern-Sternberg (1981) "Liquidity and Inflation Effects on Consumers' Expenditure", Chapter 9 in A. S. Deaton (ed.) Essays in the Theory and Measurement of Consumer Behaviour, Cambridge University Press, Cambridge, England, 237-260.

Horvath, M. T. K., and M. W. Watson (1995) "Testing for Cointegration When Some of the Cointegrating Vectors Are Prespecified", Econometric Theory, 11, 5, 984-1014.

Johansen, S. (1988) "Statistical Analysis of Cointegration Vectors", Journal of Economic Dynamics and Control, 12, 2/3, 231-254.

Johansen, S. (1991) "Estimation and Hypothesis Testing of Cointegration Vectors in Gaussian Vector Autoregressive Models", Econometrica, 59, 6, 1551-1580.

Johansen, S. (1992a) "Cointegration in Partial Systems and the Efficiency of Single-equation Analysis", Journal of Econometrics, 52, 3, 389-402.

Johansen, S. (1992b) "Testing Weak Exogeneity and the Order of Cointegration in UK Money Demand Data", Journal of Policy Modeling, 14, 3, 313-334.

Johansen, S. (1994) "The Role of the Constant and Linear Terms in Cointegration Analysis of Nonstationary Variables", Econometric Reviews, 13, 2, 205-229.

Johansen, S. (1995) Likelihood-based Inference in Cointegrated Vector Autoregressive Models, Oxford University Press, Oxford, England.

Johansen, S., and K. Juselius (1990) "Maximum Likelihood Estimation and Inference on Cointegration - With Applications to the Demand for Money", Oxford Bulletin of Economics and Statistics, 52, 2, 169-210.

Kiviet, J. F., and G. D. A. Phillips (1992) "Exact Similar Tests for Unit Roots and Cointegration", Oxford Bulletin of Economics and Statistics, 54, 3, 349-367.

Kremers, J. J. M. (1988) "Long-run Limits on the US Federal Debt", Economics Letters, $28,3,259-262$.

Kremers, J. J. M., N. R. Ericsson, and J. J. Dolado (1992) "The Power of Cointegration Tests", Oxford Bulletin of Economics and Statistics, 54, 3, 325-348.

L'Ecuyer, P. (1988) "Efficient and Portable Combined Random Number Generators", Communications of the ACM, 31, 6, 742-749 and 774 .

MacKinnon, J. G. (1991) "Critical Values for Cointegration Tests", Chapter 13 in R. F. Engle and C. W. J. Granger (eds.) Long-run Economic Relationships: Readings in Cointegration, Oxford University Press, Oxford, England, 267-276.

MacKinnon, J. G. (1994) "Approximate Asymptotic Distribution Functions for Unit-root and Cointegration Tests", Journal of Business and Economic Statistics, 12, 2, 167-176. 
MacKinnon, J. G. (1996) "Numerical Distribution Functions for Unit Root and Cointegration Tests", Journal of Applied Econometrics, 11, 6, 601-618.

MacKinnon, J. G., A. A. Haug, and L. Michelis (1999) "Numerical Distribution Functions of Likelihood Ratio Tests for Cointegration", Journal of Applied Econometrics, 14, 5, $563-577$.

MacKinnon, J. G., and H. White (1985) "Some Heteroskedasticity-consistent Covariance Matrix Estimators with Improved Finite Sample Properties", Journal of Econometrics, $29,3,305-325$.

Marsaglia, G., and T. A. Bray (1964) "A Convenient Method for Generating Normal Variables", SIAM Review, 6, 3, 260-264.

Nielsen, B., and A. Rahbek (1998) "Similarity Issues in Cointegration Analysis", Preprint No. 7, Department of Theoretical Statistics, University of Copenhagen, Copenhagen, Denmark, August.

Osterwald-Lenum, M. (1992) "A Note with Quantiles of the Asymptotic Distribution of the Maximum Likelihood Cointegration Rank Test Statistics", Oxford Bulletin of Economics and Statistics, 54, 3, 461-472.

Pesaran, M. H., Y. Shin, and R. J. Smith (1999) "Structural Analysis of Vector Error Correction Models With Exogenous I(1) Variables", Journal of Econometrics, forthcoming.

Phillips, A. W. (1954) "Stabilisation Policy in a Closed Economy", Economic Journal, 64, $254,290-323$.

Phillips, A. W. (1957) "Stabilisation Policy and the Time-forms of Lagged Responses", Economic Journal, 67, 266, 265-277.

Phillips, P. C. B., and M. Loretan (1991) "Estimating Long-run Economic Equilibria", Review of Economic Studies, 58, 3, 407-436.

Sargan, J. D. (1964) "Wages and Prices in the United Kingdom: A Study in Econometric Methodology", in P. E. Hart, G. Mills, and J. K. Whitaker (eds.) Econometric Analysis for National Economic Planning, Volume 16 of Colston Papers, Butterworths, London, 25-54 (with discussion).

Stock, J. H. (1987) "Asymptotic Properties of Least Squares Estimators of Cointegrating Vectors", Econometrica, 55, 5, 1035-1056.

Stock, J. H., and M. W. Watson (1993) "A Simple Estimator of Cointegrating Vectors in Higher Order Integrated Systems", Econometrica, 61, 4, 783-820.

Zivot, E. (1996) "The Power of Single Equation Tests for Cointegration When the Cointegrating Vector Is Prespecified", mimeo, Department of Economics, University of Washington, Seattle, Washington, November. 
Table 1. A Comparison of the Johansen, ECM, and Engle-Granger Procedures for Testing Cointegration.

\begin{tabular}{|c|c|c|c|}
\hline \multirow[t]{2}{*}{$\overline{\text { Aspect }}$} & \multicolumn{3}{|c|}{ Procedure } \\
\hline & Johansen & ECM (both types) & Engle-Granger \\
\hline Statistic & $\begin{array}{l}\text { Maximal eigenvalue } \\
\text { and trace statistics. }\end{array}$ & $\begin{array}{l}\kappa_{d}(k) ; \text { Harbo et al. } \\
\text { (1998) statistic. }\end{array}$ & $\tau_{d}(k)$ \\
\hline Assumptions & $\begin{array}{l}\text { Well-specified } \\
\text { full system. }\end{array}$ & $\begin{array}{l}\text { Weak exogeneity } \\
\text { of } z_{t} \text { for } \beta \text {. }\end{array}$ & $\begin{array}{l}\text { Common factor } \\
\text { restriction. }\end{array}$ \\
\hline Advantages & $\begin{array}{l}\text { Maximum likelihood } \\
\text { of full system. } \\
\text { Determines } r \text { (the } \\
\text { number of } \\
\text { cointegrating vectors), } \\
\beta \text {, and } \alpha \text {. }\end{array}$ & $\begin{array}{l}\text { Starting point for } \\
\text { ECM modeling; } \\
\text { unrestrictive dynamics. } \\
\text { Weak exogeneity often } \\
\text { is valid empirically. } \\
\text { Robust to particulars } \\
\text { of the marginal process. }\end{array}$ & $\begin{array}{l}\text { Intuitive. } \\
\text { Super-consistent } \\
\text { estimator of } \beta \text {. }\end{array}$ \\
\hline Disadvantages & $\begin{array}{l}\text { Full system should } \\
\text { be well-specified. }\end{array}$ & $\begin{array}{l}\text { Weak exogeneity } \\
\text { is assumed. } \\
r \leq 1 \text { is imposed } \\
\text { (usually). }\end{array}$ & $\begin{array}{l}\text { Comfac often is invalid. } \\
\text { Inferences on } \beta \text { are messy. } \\
\text { Biases in estimating } \beta \text {. } \\
r \leq 1 \text { imposed (usually). } \\
\text { Normalization affects } \\
\text { estimation. Dynamics } \\
\text { may be of interest. }\end{array}$ \\
\hline $\begin{array}{l}\text { Sources for } \\
\text { critical values } \\
\text { and } p \text {-values }\end{array}$ & $\begin{array}{l}\text { Johansen (1988, 1995), } \\
\text { Johansen and Juselius } \\
\text { (1990), } \\
\text { Osterwald-Lenum (1992), } \\
\text { Doornik (1998, 1999), } \\
\text { MacKinnon et al. (1999). }\end{array}$ & $\begin{array}{l}\text { Banerjee et al. (1993), } \\
\text { Banerjee et al. (1998), } \\
\text { this paper; } \\
\text { Harbo et al. (1998), } \\
\text { Pesaran et al. (1999), } \\
\text { MacKinnon et al. (1999). }\end{array}$ & $\begin{array}{l}\text { Engle and Granger (1987), } \\
\text { MacKinnon (1991), } \\
\text { MacKinnon (1994), } \\
\text { MacKinnon (1996). }\end{array}$ \\
\hline
\end{tabular}


Table 2. Response Surface Estimates for Critical Values of the ECM Test of Cointegration $\kappa_{n c}(k)$

(no deterministic terms).

\begin{tabular}{|c|c|c|c|c|c|c|c|}
\hline$k$ & size & $\theta_{\infty}$ & (s.e.) & $\theta_{1}$ & $\theta_{2}$ & $\theta_{3}$ & $\hat{\sigma}$ \\
\hline \multirow[t]{3}{*}{1} & $1 \%$ & -2.5659 & $(0.0006)$ & -2.19 & -3.6 & 26. & 0.00843 \\
\hline & $5 \%$ & -1.9408 & $(0.0003)$ & -0.35 & 0.6 & -17 . & 0.00430 \\
\hline & $10 \%$ & -1.6167 & (0.0003) & 0.23 & -1.0 & -6 & 0.00339 \\
\hline \multirow[t]{3}{*}{2} & $1 \%$ & -3.2106 & $(0.0006)$ & -4.69 & -10.5 & 48. & 0.00845 \\
\hline & $5 \%$ & -2.5937 & $(0.0003)$ & -1.53 & -0.8 & -24 & 0.00439 \\
\hline & $10 \%$ & -2.2643 & $(0.0003)$ & -0.41 & -1.5 & -9 . & 0.00350 \\
\hline \multirow[t]{3}{*}{3} & $1 \%$ & -3.6215 & $(0.0006)$ & -6.14 & -5.3 & -67 . & 0.00892 \\
\hline & $5 \%$ & -3.0048 & $(0.0003)$ & -2.11 & 2.1 & -61 . & 0.00468 \\
\hline & $10 \%$ & -2.6744 & $(0.0003)$ & -0.57 & 1.2 & -44 & 0.00372 \\
\hline \multirow[t]{3}{*}{4} & $1 \%$ & -3.9433 & $(0.0006)$ & -7.15 & -3.1 & -69 . & 0.00929 \\
\hline & $5 \%$ & -3.3268 & (0.0003) & -2.04 & -6.4 & 19. & 0.00455 \\
\hline & $10 \%$ & -2.9942 & $(0.0003)$ & -0.21 & -5.1 & 13. & 0.00377 \\
\hline \multirow[t]{3}{*}{5} & $1 \%$ & -4.2168 & $(0.0005)$ & -7.66 & -2.1 & -87. & 0.00920 \\
\hline & $5 \%$ & -3.5978 & $(0.0003)$ & -1.92 & -3.6 & -17 . & 0.00502 \\
\hline & $10 \%$ & -3.2637 & $(0.0003)$ & 0.25 & -4.2 & -15. & 0.00405 \\
\hline \multirow[t]{3}{*}{6} & $1 \%$ & -4.4585 & $(0.0006)$ & -7.72 & -7.2 & -57 . & 0.01034 \\
\hline & $5 \%$ & -3.8373 & $(0.0003)$ & -1.38 & -7.7 & -6 . & 0.00519 \\
\hline & $10 \%$ & -3.5022 & $(0.0002)$ & 1.15 & -11.1 & 12. & 0.00397 \\
\hline \multirow[t]{3}{*}{7} & $1 \%$ & -4.6763 & $(0.0005)$ & -7.78 & -5.1 & -73. & 0.01122 \\
\hline & $5 \%$ & -4.0535 & $(0.0003)$ & -0.76 & -10.0 & -7 & 0.00567 \\
\hline & $10 \%$ & -3.7165 & $(0.0002)$ & 2.04 & -14.7 & 15. & 0.00421 \\
\hline \multirow[t]{3}{*}{8} & $1 \%$ & -4.8772 & $(0.0006)$ & -7.64 & -2.4 & -116. & 0.01035 \\
\hline & $5 \%$ & -4.2513 & $(0.0003)$ & -0.03 & -12.0 & -19 & 0.00543 \\
\hline & $10 \%$ & -3.9135 & $(0.0002)$ & 3.10 & -20.3 & 25. & 0.00420 \\
\hline \multirow[t]{3}{*}{9} & $1 \%$ & -5.0634 & $(0.0006)$ & -7.13 & -6.9 & -113 & 0.01009 \\
\hline & $5 \%$ & -4.4363 & $(0.0003)$ & 1.00 & -18.4 & -8 & 0.00534 \\
\hline & $10 \%$ & -4.0974 & $(0.0003)$ & 4.46 & -32.1 & 74. & 0.00422 \\
\hline \multirow[t]{3}{*}{10} & $1 \%$ & -5.2381 & $(0.0006)$ & -6.68 & -4.7 & -149. & 0.01035 \\
\hline & $5 \%$ & -4.6093 & $(0.0003)$ & 2.11 & -25.4 & 10. & 0.00552 \\
\hline & $10 \%$ & -4.2693 & $(0.0003)$ & 5.76 & -38.2 & 72. & 0.00419 \\
\hline \multirow[t]{3}{*}{11} & $1 \%$ & -5.4039 & $(0.0006)$ & -6.05 & -7.1 & -163. & 0.01038 \\
\hline & $5 \%$ & -4.7734 & $(0.0004)$ & 3.37 & -35.4 & 48. & 0.00556 \\
\hline & $10 \%$ & -4.4324 & $(0.0003)$ & 7.33 & -53.3 & 145. & 0.00426 \\
\hline \multirow[t]{3}{*}{12} & $1 \%$ & -5.5598 & $(0.0006)$ & -5.10 & -19.4 & -75. & 0.01040 \\
\hline & $5 \%$ & -4.9279 & $(0.0004)$ & 4.77 & -48.8 & 109. & 0.00579 \\
\hline & $10 \%$ & -4.5864 & $(0.0003)$ & 8.96 & -68.0 & 204. & 0.00439 \\
\hline
\end{tabular}


Table 3. Response Surface Estimates for Critical Values of the ECM Test of Cointegration $\kappa_{c}(k)$

(with a constant term).

\begin{tabular}{|c|c|c|c|c|c|c|c|}
\hline$k$ & size & $\theta_{\infty}$ & (s.e.) & $\theta_{1} \theta_{1}$ & $\theta_{2}$ & $\bar{\theta}_{3}$ & $\hat{\sigma}$ \\
\hline \multirow[t]{3}{*}{1} & $1 \%$ & -3.4307 & $(0.0006)$ & -6.52 & -4.7 & -10. & 0.00790 \\
\hline & $5 \%$ & -2.8617 & $(0.0003)$ & -2.81 & -3.2 & 37. & 0.00431 \\
\hline & $10 \%$ & -2.5668 & $(0.0003)$ & -1.56 & 2.1 & -29 . & 0.00332 \\
\hline \multirow[t]{3}{*}{2} & $1 \%$ & -3.7948 & $(0.0006)$ & -7.87 & -3.6 & -28 . & 0.00847 \\
\hline & $5 \%$ & -3.2145 & $(0.0003)$ & -3.21 & -2.0 & 17. & 0.00438 \\
\hline & $10 \%$ & -2.9083 & $(0.0002)$ & -1.55 & 1.9 & -25 . & 0.00338 \\
\hline \multirow[t]{3}{*}{3} & $1 \%$ & -4.0947 & $(0.0005)$ & -8.59 & -2.0 & -65 . & 0.00857 \\
\hline & $5 \%$ & -3.5057 & $(0.0003)$ & -3.27 & 1.1 & -34 . & 0.00462 \\
\hline & $10 \%$ & -3.1924 & $(0.0002)$ & -1.23 & 2.1 & -39 . & 0.00364 \\
\hline \multirow[t]{3}{*}{4} & $1 \%$ & -4.3555 & $(0.0006)$ & -8.90 & -6.7 & -31 . & 0.00959 \\
\hline & $5 \%$ & -3.7592 & $(0.0003)$ & -2.92 & -3.7 & 5. & 0.00484 \\
\hline & $10 \%$ & -3.4412 & $(0.0002)$ & -0.53 & -4.5 & 4. & 0.00388 \\
\hline \multirow[t]{3}{*}{5} & $1 \%$ & -4.5859 & $(0.0005)$ & -9.14 & -2.5 & -78 . & 0.00970 \\
\hline & $5 \%$ & -3.9856 & $(0.0003)$ & -2.50 & -1.7 & -35 . & 0.00493 \\
\hline & $10 \%$ & -3.6635 & $(0.0002)$ & 0.21 & -6.0 & -8 . & 0.00407 \\
\hline \multirow[t]{3}{*}{6} & $1 \%$ & -4.7970 & $(0.0005)$ & -9.04 & -5.6 & -66 . & 0.01100 \\
\hline & $5 \%$ & -4.1922 & $(0.0003)$ & -1.73 & -7.8 & -9 . & 0.00514 \\
\hline & $10 \%$ & -3.8670 & $(0.0002)$ & 1.26 & -12.7 & 14. & 0.00402 \\
\hline \multirow[t]{3}{*}{7} & $1 \%$ & -4.9912 & $(0.0005)$ & -8.85 & -5.1 & -72 . & 0.01222 \\
\hline & $5 \%$ & -4.3831 & $(0.0003)$ & -0.90 & -12.2 & 1. & 0.00606 \\
\hline & $10 \%$ & -4.0556 & $(0.0002)$ & 2.39 & -18.8 & 27 . & 0.00437 \\
\hline \multirow[t]{3}{*}{8} & $1 \%$ & -5.1723 & $(0.0006)$ & -8.58 & -2.0 & -113. & 0.01149 \\
\hline & $5 \%$ & -4.5608 & $(0.0003)$ & 0.02 & -15.4 & -2 . & 0.00571 \\
\hline & $10 \%$ & -4.2310 & $(0.0002)$ & 3.59 & -25.6 & 44 . & 0.00427 \\
\hline \multirow[t]{3}{*}{9} & $1 \%$ & -5.3437 & $(0.0006)$ & -7.86 & -7.8 & -101 . & 0.01045 \\
\hline & $5 \%$ & -4.7287 & $(0.0003)$ & 1.25 & -26.0 & 42. & 0.00531 \\
\hline & $10 \%$ & -4.3975 & $(0.0002)$ & 5.11 & -39.2 & 104. & 0.00399 \\
\hline \multirow[t]{3}{*}{10} & $1 \%$ & -5.5048 & $(0.0006)$ & -7.19 & -9.8 & -102 . & 0.01059 \\
\hline & $5 \%$ & -4.8876 & $(0.0003)$ & 2.46 & -31.7 & 43. & 0.00545 \\
\hline & $10 \%$ & -4.5543 & $(0.0002)$ & 6.53 & -47.2 & 116. & 0.00438 \\
\hline \multirow[t]{3}{*}{11} & $1 \%$ & -5.6588 & $(0.0006)$ & -6.39 & -13.7 & -105 . & 0.01038 \\
\hline & $5 \%$ & -5.0394 & $(0.0004)$ & 3.88 & -45.7 & 117. & 0.00579 \\
\hline & $10 \%$ & -4.7055 & $(0.0003)$ & 8.31 & -66.5 & 222 . & 0.00443 \\
\hline \multirow[t]{3}{*}{12} & $1 \%$ & -5.8068 & $(0.0006)$ & -5.13 & -29.2 & -15 . & 0.01060 \\
\hline & $5 \%$ & -5.1836 & $(0.0003)$ & 5.33 & -55.9 & 134. & 0.00555 \\
\hline & $10 \%$ & -4.8480 & $(0.0003)$ & 9.94 & -78.0 & 240. & 0.00431 \\
\hline
\end{tabular}


Table 4. Response Surface Estimates for Critical Values of the ECM Test of Cointegration $\kappa_{c t}(k)$

(with a constant term and a linear trend).

\begin{tabular}{|c|c|c|c|c|c|c|c|}
\hline $\bar{~} k$ & size & $\theta_{\infty}$ & (s.e.) & 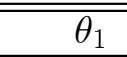 & $\bar{c}_{2}$ & $\theta_{3}$ & $\hat{\sigma}$ \\
\hline \multirow[t]{3}{*}{1} & $1 \%$ & -3.9593 & $(0.0005)$ & -8.99 & -4.9 & 39. & 0.00805 \\
\hline & $5 \%$ & -3.4108 & $(0.0003)$ & -4.38 & 4.5 & -21 & 0.00412 \\
\hline & $10 \%$ & -3.1272 & $(0.0002)$ & -2.57 & 3.5 & -7 . & 0.00324 \\
\hline \multirow[t]{3}{*}{2} & $1 \%$ & -4.2488 & $(0.0005)$ & -10.04 & -4.1 & -1 . & 0.00845 \\
\hline & $5 \%$ & -3.6873 & $(0.0003)$ & -4.56 & 2.2 & 1. & 0.00442 \\
\hline & $10 \%$ & -3.3927 & $(0.0002)$ & -2.41 & 3.4 & -14 & 0.00339 \\
\hline \multirow[t]{3}{*}{3} & $1 \%$ & -4.4981 & $(0.0006)$ & -10.69 & 0.6 & -58 & 0.00931 \\
\hline & $5 \%$ & -3.9263 & $(0.0003)$ & -4.47 & 5.2 & -38 & 0.00474 \\
\hline & $10 \%$ & -3.6249 & $(0.0002)$ & -1.86 & 1.1 & -10 & 0.00356 \\
\hline \multirow[t]{3}{*}{4} & $1 \%$ & -4.7214 & $(0.0006)$ & -10.94 & 1.6 & -77 . & 0.00949 \\
\hline & $5 \%$ & -4.1421 & $(0.0003)$ & -3.99 & 2.8 & -35 . & 0.00496 \\
\hline & $10 \%$ & -3.8342 & $(0.0002)$ & -1.16 & 0.4 & -23 . & 0.00368 \\
\hline \multirow[t]{3}{*}{5} & $1 \%$ & -4.9255 & $(0.0005)$ & -10.86 & 1.2 & -94 . & 0.01018 \\
\hline & $5 \%$ & -4.3392 & $(0.0003)$ & -3.37 & 1.6 & -47 . & 0.00510 \\
\hline & $10 \%$ & -4.0271 & $(0.0002)$ & -0.17 & -4.4 & -14 & 0.00406 \\
\hline \multirow[t]{3}{*}{6} & $1 \%$ & -5.1137 & $(0.0005)$ & -10.72 & 1.4 & -96 . & 0.01145 \\
\hline & $5 \%$ & -4.5227 & $(0.0003)$ & -2.52 & -2.8 & -32 . & 0.00536 \\
\hline & $10 \%$ & -4.2067 & $(0.0002)$ & 0.94 & -9.9 & 0. & 0.00415 \\
\hline \multirow[t]{3}{*}{7} & $1 \%$ & -5.2923 & $(0.0005)$ & -10.11 & -4.0 & -75 & 0.01397 \\
\hline & $5 \%$ & -4.6952 & $(0.0003)$ & -1.43 & -10.6 & -5 . & 0.00625 \\
\hline & $10 \%$ & -4.3751 & $(0.0002)$ & 2.18 & -16.9 & 18. & 0.00468 \\
\hline \multirow[t]{3}{*}{8} & $1 \%$ & -5.4565 & $(0.0006)$ & -9.77 & -1.5 & -106 & 0.01202 \\
\hline & $5 \%$ & -4.8569 & $(0.0003)$ & -0.43 & -14.4 & -3 . & 0.00593 \\
\hline & $10 \%$ & -4.5344 & $(0.0002)$ & 3.52 & -24.9 & 40. & 0.00453 \\
\hline \multirow[t]{3}{*}{9} & $1 \%$ & -5.6149 & $(0.0006)$ & -9.11 & -2.0 & -126 & 0.01050 \\
\hline & $5 \%$ & -5.0108 & $(0.0003)$ & 0.78 & -21.2 & 12. & 0.00554 \\
\hline & $10 \%$ & -4.6864 & $(0.0003)$ & 5.08 & -37.2 & 88. & 0.00430 \\
\hline \multirow[t]{3}{*}{10} & $1 \%$ & -5.7657 & $(0.0006)$ & -8.28 & -5.3 & -121 . & 0.01180 \\
\hline & $5 \%$ & -5.1582 & $(0.0003)$ & 2.12 & -28.6 & 26. & 0.00558 \\
\hline & $10 \%$ & -4.8311 & $(0.0002)$ & 6.62 & -46.2 & 103. & 0.00438 \\
\hline \multirow[t]{3}{*}{11} & $1 \%$ & -5.9099 & $(0.0006)$ & -7.41 & -6.2 & -160 . & 0.01088 \\
\hline & $5 \%$ & -5.2992 & $(0.0003)$ & 3.57 & -40.0 & 69. & 0.00552 \\
\hline & $10 \%$ & -4.9707 & $(0.0003)$ & 8.41 & -64.7 & 199. & 0.00461 \\
\hline \multirow[t]{3}{*}{12} & $1 \%$ & -6.0478 & $(0.0006)$ & -6.17 & -20.6 & -74 & 0.01111 \\
\hline & $5 \%$ & -5.4346 & $(0.0003)$ & 5.22 & -54.5 & 121. & 0.00605 \\
\hline & $10 \%$ & -5.1046 & $(0.0003)$ & 10.20 & -78.3 & 231. & 0.00451 \\
\hline
\end{tabular}


Table 5. Response Surface Estimates for Critical Values of the ECM Test of Cointegration $\kappa_{c t t}(k)$

(with a constant term, linear trend, and quadratic trend).

\begin{tabular}{|c|c|c|c|c|c|c|c|}
\hline $\bar{~} k$ & size & $\theta_{\infty}$ & (s.e.) & 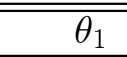 & $\overline{\theta_{2}}$ & $\theta_{3}$ & $\hat{\sigma}$ \\
\hline \multirow[t]{3}{*}{1} & $1 \%$ & -4.3714 & $(0.0006)$ & -11.57 & 7.4 & -66. & 0.00849 \\
\hline & $5 \%$ & -3.8324 & $(0.0003)$ & -5.90 & 9.3 & -29 . & 0.00430 \\
\hline & $10 \%$ & -3.5534 & $(0.0002)$ & -3.63 & 6.6 & -7 . & 0.00341 \\
\hline \multirow[t]{3}{*}{2} & $1 \%$ & -4.6190 & $(0.0005)$ & -12.44 & 11.6 & -130 . & 0.00855 \\
\hline & $5 \%$ & -4.0683 & $(0.0003)$ & -5.90 & 9.3 & -39 . & 0.00445 \\
\hline & $10 \%$ & -3.7800 & $(0.0002)$ & -3.28 & 7.8 & -36 & 0.00344 \\
\hline \multirow[t]{3}{*}{3} & $1 \%$ & -4.8399 & $(0.0005)$ & -12.71 & 10.7 & -136 . & 0.00934 \\
\hline & $5 \%$ & -4.2790 & $(0.0003)$ & -5.56 & 9.3 & -55 . & 0.00481 \\
\hline & $10 \%$ & -3.9833 & $(0.0002)$ & -2.61 & 6.6 & -42 . & 0.00367 \\
\hline \multirow[t]{3}{*}{4} & $1 \%$ & -5.0396 & $(0.0005)$ & -12.86 & 13.0 & -149 . & 0.01000 \\
\hline & $5 \%$ & -4.4716 & $(0.0003)$ & -4.95 & 6.9 & -50 . & 0.00496 \\
\hline & $10 \%$ & -4.1701 & $(0.0002)$ & -1.72 & 3.8 & -37 . & 0.00389 \\
\hline \multirow[t]{3}{*}{5} & $1 \%$ & -5.2256 & $(0.0005)$ & -12.61 & 8.3 & -121 & 0.01061 \\
\hline & $5 \%$ & -4.6498 & $(0.0003)$ & -4.23 & 5.7 & -58 . & 0.00536 \\
\hline & $10 \%$ & -4.3438 & $(0.0002)$ & -0.64 & -1.0 & -27 . & 0.00401 \\
\hline \multirow[t]{3}{*}{6} & $1 \%$ & -5.3998 & $(0.0005)$ & -12.12 & 4.3 & -105 . & 0.01270 \\
\hline & $5 \%$ & -4.8177 & $(0.0003)$ & -3.22 & -0.4 & -36 & 0.00590 \\
\hline & $10 \%$ & -4.5073 & $(0.0002)$ & 0.60 & -7.7 & -7 & 0.00430 \\
\hline \multirow[t]{3}{*}{7} & $1 \%$ & -5.5652 & $(0.0005)$ & -11.31 & -4.0 & -71 & 0.01776 \\
\hline & $5 \%$ & -4.9774 & $(0.0003)$ & -1.96 & -9.3 & -8 . & 0.00671 \\
\hline & $10 \%$ & -4.6629 & $(0.0002)$ & 2.02 & -16.1 & 15. & 0.00494 \\
\hline \multirow[t]{3}{*}{8} & $1 \%$ & -5.7181 & $(0.0006)$ & -10.97 & 0.8 & -108 & 0.01143 \\
\hline & $5 \%$ & -5.1265 & $(0.0003)$ & -0.96 & -10.9 & -17 . & 0.00584 \\
\hline & $10 \%$ & -4.8098 & $(0.0002)$ & 3.41 & -23.3 & 31. & 0.00457 \\
\hline \multirow[t]{3}{*}{9} & $1 \%$ & -5.8656 & $(0.0006)$ & -10.32 & 4.3 & -151 . & 0.01103 \\
\hline & $5 \%$ & -5.2703 & $(0.0003)$ & 0.33 & -16.2 & -17 . & 0.00565 \\
\hline & $10 \%$ & -4.9510 & $(0.0003)$ & 5.04 & -35.4 & 74. & 0.00435 \\
\hline \multirow[t]{3}{*}{10} & $1 \%$ & -6.0083 & $(0.0006)$ & -9.26 & -4.0 & -117 . & 0.01218 \\
\hline & $5 \%$ & -5.4083 & $(0.0003)$ & 1.80 & -26.5 & 17. & 0.00589 \\
\hline & $10 \%$ & -5.0863 & $(0.0002)$ & 6.63 & -43.9 & 85. & 0.00440 \\
\hline \multirow[t]{3}{*}{11} & $1 \%$ & -6.1449 & $(0.0006)$ & -8.26 & -4.7 & -158 . & 0.01155 \\
\hline & $5 \%$ & -5.5415 & $(0.0003)$ & 3.38 & -39.0 & 60 & 0.00587 \\
\hline & $10 \%$ & -5.2176 & $(0.0003)$ & 8.54 & -63.7 & 179. & 0.00467 \\
\hline \multirow[t]{3}{*}{12} & $1 \%$ & -6.2746 & $(0.0006)$ & -7.13 & -13.5 & -111. & 0.01281 \\
\hline & $5 \%$ & -5.6697 & $(0.0003)$ & 5.12 & -54.1 & 117. & 0.00615 \\
\hline & $10 \%$ & -5.3436 & $(0.0002)$ & 10.36 & -76.3 & 206. & 0.00462 \\
\hline
\end{tabular}


Table 6. Empirical $t$-values, Critical Values, and $p$-values for the ECM Statistic:

Models of U.K. Narrow Money Demand.

\begin{tabular}{|c|c|c|c|c|c|c|c|c|c|}
\hline \multirow{2}{*}{$\begin{array}{l}\text { Statistic } \\
\text { Model or } \\
\text { calculation } \\
\end{array}$} & \multirow{2}{*}{$\begin{array}{c}\text { Empirical } \\
t \text {-value }\end{array}$} & \multirow[t]{2}{*}{$h$} & \multicolumn{3}{|c|}{ Critical value } & \multicolumn{2}{|c|}{$p$-value } & \multirow[t]{2}{*}{$\overline{\hat{\sigma}}$} & \multirow{2}{*}{$\begin{array}{c}F \text {-statistic } \\
\text { versus the model } \\
\text { for } \kappa_{c t t}(4)\end{array}$} \\
\hline & & & $1 \%$ & $5 \%$ & $10 \%$ & $\begin{array}{c}\text { finite } \\
\text { sample }\end{array}$ & $\begin{array}{c}\text { asymp- } \\
\text { totic }\end{array}$ & & \\
\hline \multicolumn{10}{|l|}{$\kappa_{c t t}(4)$} \\
\hline $\mathrm{ADL}$ & -3.29 & 26 & -5.21 & -4.54 & -4.19 & 0.3859 & 0.4140 & $1.313 \%$ & - \\
\hline ECM & -3.14 & 8 & -5.18 & -4.52 & -4.19 & 0.4544 & 0.4819 & $1.326 \%$ & - \\
\hline Asymptotic & & & -5.04 & -4.47 & -4.17 & & & & \\
\hline Crude & & & -5.0 & -4.4 & -4.1 & & & & \\
\hline \multicolumn{10}{|l|}{$\kappa_{c t}(4)$} \\
\hline $\mathrm{ADL}$ & $-5.14^{* *}$ & 25 & -4.87 & -4.19 & -3.85 & 0.0047 & 0.0024 & $1.306 \%$ & $F(1,74)=0.11[0.74]$ \\
\hline ECM & $-6.53^{* *}$ & 7 & -4.84 & -4.18 & -3.85 & 0.0000 & 0.0000 & $1.320 \%$ & $F(1,92)=0.16[0.69]$ \\
\hline Asymptotic & & & -4.72 & -4.14 & -3.83 & & & & \\
\hline Crude & & & -4.7 & -4.1 & -3.8 & & & & \\
\hline \multicolumn{10}{|l|}{$\kappa_{c}(4)$} \\
\hline $\mathrm{ADL}$ & $-5.17^{* *}$ & 24 & -4.47 & -3.80 & -3.45 & 0.0014 & 0.0006 & $1.301 \%$ & $F(2,74)=0.28[0.76]$ \\
\hline $\mathrm{ECM}$ & $-7.78^{* *}$ & 6 & -4.45 & -3.79 & -3.45 & 0.0000 & 0.0000 & $1.317 \%$ & $F(2,92)=0.37[0.69]$ \\
\hline Asymptotic & & & -4.36 & -3.76 & -3.44 & & & & \\
\hline Crude & & & -4.4 & -3.8 & -3.5 & & & & \\
\hline \multicolumn{10}{|l|}{$\kappa_{n c}(4)$} \\
\hline $\mathrm{ADL}$ & $-6.10^{* *}$ & 23 & -4.04 & -3.35 & -3.00 & 0.0000 & 0.0000 & $1.297 \%$ & $F(3,74)=0.36[0.78]$ \\
\hline ECM & $-10.57^{* *}$ & 5 & -4.02 & -3.35 & -3.00 & 0.0000 & 0.0000 & $1.311 \%$ & $F(3,92)=0.31[0.82]$ \\
\hline Asymptotic & & & -3.94 & -3.33 & -2.99 & & & & \\
\hline Crude & & & -4.1 & -3.5 & -3.2 & & & & \\
\hline
\end{tabular}


Table 7. Empirical $t$-values, Critical Values, and $p$-values for the ECM Statistic:

Models of U.K. Consumers' Expenditure.

\begin{tabular}{|c|c|c|c|c|c|c|c|c|c|}
\hline \multirow{2}{*}{$\begin{array}{l}\text { Statistic } \\
\text { Model or } \\
\text { calculation } \\
\end{array}$} & \multirow{2}{*}{$\begin{array}{c}\text { Empirical } \\
t \text {-value }\end{array}$} & \multirow[t]{2}{*}{$h$} & \multicolumn{3}{|c|}{ Critical value } & \multicolumn{2}{|c|}{$p$-value } & \multirow[t]{2}{*}{$\hat{\sigma}$} & \multirow{2}{*}{$\begin{array}{c}F \text {-statistic } \\
\text { versus the model } \\
\text { for } \kappa_{c t t}(3)\end{array}$} \\
\hline & & & $1 \%$ & $5 \%$ & $10 \%$ & $\begin{array}{c}\text { finite } \\
\text { sample }\end{array}$ & $\begin{array}{c}\text { asymp- } \\
\text { totic }\end{array}$ & & \\
\hline \multicolumn{10}{|l|}{$\kappa_{c t t}(3)$} \\
\hline $\mathrm{ADL}$ & -2.11 & 20 & -5.09 & -4.38 & -4.03 & 0.8107 & 0.8482 & $0.559 \%$ & - \\
\hline $\mathrm{ECM}$ & -2.54 & 10 & -5.05 & -4.37 & -4.02 & 0.6570 & 0.6949 & $0.548 \%$ & - \\
\hline $\mathrm{ADL}+Q_{i}$ & -1.99 & 23 & -5.10 & -4.39 & -4.04 & 0.8439 & 0.8796 & $0.508 \%$ & - \\
\hline $\mathrm{ECM}+Q_{i}$ & -2.95 & 13 & -5.06 & -4.37 & -4.03 & 0.4683 & 0.4999 & $0.537 \%$ & - \\
\hline Asymptotic & & & -4.84 & -4.28 & -3.98 & & & & \\
\hline Crude & & & -4.8 & -4.2 & -3.9 & & & & \\
\hline \multicolumn{10}{|l|}{$\kappa_{c t}(3)$} \\
\hline $\mathrm{ADL}$ & -2.83 & 19 & -4.70 & -4.01 & -3.66 & 0.3542 & 0.3753 & $0.560 \%$ & $F(1,51)=1.29[0.26]$ \\
\hline ECM & -1.88 & 9 & -4.67 & -4.00 & -3.65 & 0.7585 & 0.7870 & $0.581 \%$ & $F(1,61)=8.70[0.00]$ \\
\hline $\mathrm{ADL}+Q_{i}$ & -2.77 & 22 & -4.72 & -4.02 & -3.66 & 0.3787 & 0.4035 & $0.512 \%$ & $F(1,48)=1.72[0.20]$ \\
\hline $\mathrm{ECM}+Q_{i}$ & $-3.86^{+}$ & 12 & -4.68 & -4.00 & -3.66 & 0.0675 & 0.0593 & $0.544 \%$ & $F(1,58)=2.63[0.11]$ \\
\hline Asymptotic & & & -4.50 & -3.93 & -3.62 & & & & \\
\hline Crude & & & -4.5 & -3.9 & -3.6 & & & & \\
\hline \multicolumn{10}{|l|}{$\kappa_{c}(3)$} \\
\hline $\mathrm{ADL}$ & -1.51 & 18 & -4.26 & -3.57 & -3.22 & 0.7027 & 0.7299 & $0.586 \%$ & $F(2,51)=3.60[0.03]$ \\
\hline ECM & -1.59 & 8 & -4.23 & -3.56 & -3.21 & 0.6760 & 0.6996 & $0.586 \%$ & $F(2,61)=5.46[0.01]$ \\
\hline $\mathrm{ADL}+Q_{i}$ & -1.43 & 21 & -4.27 & -3.57 & -3.22 & 0.7275 & 0.7554 & $0.536 \%$ & $F(2,48)=3.76[0.03]$ \\
\hline $\mathrm{ECM}+Q_{i}$ & $-3.45^{+}$ & 11 & -4.24 & -3.56 & -3.21 & 0.0629 & 0.0571 & $0.559 \%$ & $F(2,58)=3.57[0.03]$ \\
\hline Asymptotic & & & -4.09 & -3.51 & -3.19 & & & & \\
\hline Crude & & & -4.2 & -3.6 & -3.3 & & & & \\
\hline \multicolumn{10}{|l|}{$\kappa_{n c}(3)$} \\
\hline $\mathrm{ADL}$ & -2.31 & 17 & -3.74 & -3.04 & -2.68 & 0.1846 & 0.1882 & $0.581 \%$ & $F(3,51)=2.49[0.07]$ \\
\hline $\mathrm{ECM}$ & -2.31 & 7 & -3.72 & -3.04 & -2.68 & 0.1845 & 0.1875 & $0.591 \%$ & $F(3,61)=4.42[0.01]$ \\
\hline $\mathrm{ADL}+Q_{i}$ & -2.37 & 20 & -3.74 & -3.05 & -2.69 & 0.1674 & 0.1700 & $0.531 \%$ & $F(3,48)=2.56[0.07]$ \\
\hline $\mathrm{ECM}+Q_{i}$ & $-3.90^{* *}$ & 10 & -3.72 & -3.04 & -2.68 & 0.0062 & 0.0042 & $0.563 \%$ & $F(3,58)=3.04[0.04]$ \\
\hline Asymptotic & & & -3.62 & -3.00 & -2.67 & & & & \\
\hline Crude & & & -3.9 & -3.3 & -3.0 & & & & \\
\hline
\end{tabular}


Table 8. Empirical $t$-values, Critical Values, and $p$-values for the ECM Statistic:

Models of U.S. Federal Government Debt.

\begin{tabular}{|c|c|c|c|c|c|c|c|c|c|}
\hline \multirow{2}{*}{$\begin{array}{l}\text { Statistic } \\
\text { Model or } \\
\text { calculation } \\
\end{array}$} & \multirow{2}{*}{$\begin{array}{c}\text { Empirical } \\
t \text {-value }\end{array}$} & \multirow[t]{2}{*}{$\bar{h}$} & \multicolumn{3}{|c|}{ Critical value } & \multicolumn{2}{|c|}{$p$-value } & \multirow[t]{2}{*}{$\hat{\sigma}$} & \multirow{2}{*}{$\begin{array}{c}F \text {-statistic } \\
\text { versus the model } \\
\text { for } \kappa_{c t t}(2) \\
\end{array}$} \\
\hline & & & $1 \%$ & $5 \%$ & $10 \%$ & $\begin{array}{c}\text { finite } \\
\text { sample }\end{array}$ & $\begin{array}{c}\text { asymp- } \\
\text { totic }\end{array}$ & & \\
\hline \multicolumn{10}{|l|}{$\kappa_{c t t}(2)$} \\
\hline ADL+bubble & -1.36 & 6 & -5.34 & -4.39 & -3.95 & 0.9247 & 0.9651 & 7.40 & - \\
\hline $\mathrm{ADL}$ & -2.96 & 7 & -5.38 & -4.41 & -3.96 & 0.3688 & 0.4121 & 6.37 & - \\
\hline Asymptotic & & & -4.62 & -4.07 & -3.78 & & & & \\
\hline Crude & & & -4.6 & -4.0 & -3.7 & & & & \\
\hline \multicolumn{10}{|l|}{$\kappa_{c t}(2)$} \\
\hline ADL+bubble & -1.36 & 6 & -4.85 & -3.95 & -3.53 & 0.8386 & 0.8947 & 7.40 & - \\
\hline $\mathrm{ADL}$ & -1.38 & 6 & -4.85 & -3.95 & -3.53 & 0.8308 & 0.8886 & 7.38 & $F(1,16)=6.82[0.02]$ \\
\hline Asymptotic & & & -4.25 & -3.69 & -3.39 & & & & \\
\hline Crude & & & -4.3 & -3.7 & -3.4 & & & & \\
\hline \multicolumn{10}{|l|}{$\kappa_{c}(2)$} \\
\hline ADL+bubble & - & & & & & & & & \\
\hline $\mathrm{ADL}$ & -1.50 & 5 & -4.25 & -3.40 & -2.99 & 0.5944 & 0.6458 & 7.43 & $F(2,16)=4.26[0.03]$ \\
\hline Asymptotic & & & -3.79 & -3.21 & -2.91 & & & & \\
\hline Crude & & & -4.0 & -3.4 & -3.1 & & & & \\
\hline \multicolumn{10}{|l|}{$\kappa_{n c}(2)$} \\
\hline ADL+bubble & - & & & & & & & & \\
\hline $\mathrm{ADL}$ & +2.58 & 4 & -3.48 & -2.68 & -2.29 & 0.9984 & 0.9992 & 7.94 & $F(3,16)=4.52[0.02]$ \\
\hline Asymptotic & & & -3.21 & -2.59 & -2.26 & & & & \\
\hline Crude & & & -3.7 & -3.1 & -2.8 & & & & \\
\hline
\end{tabular}




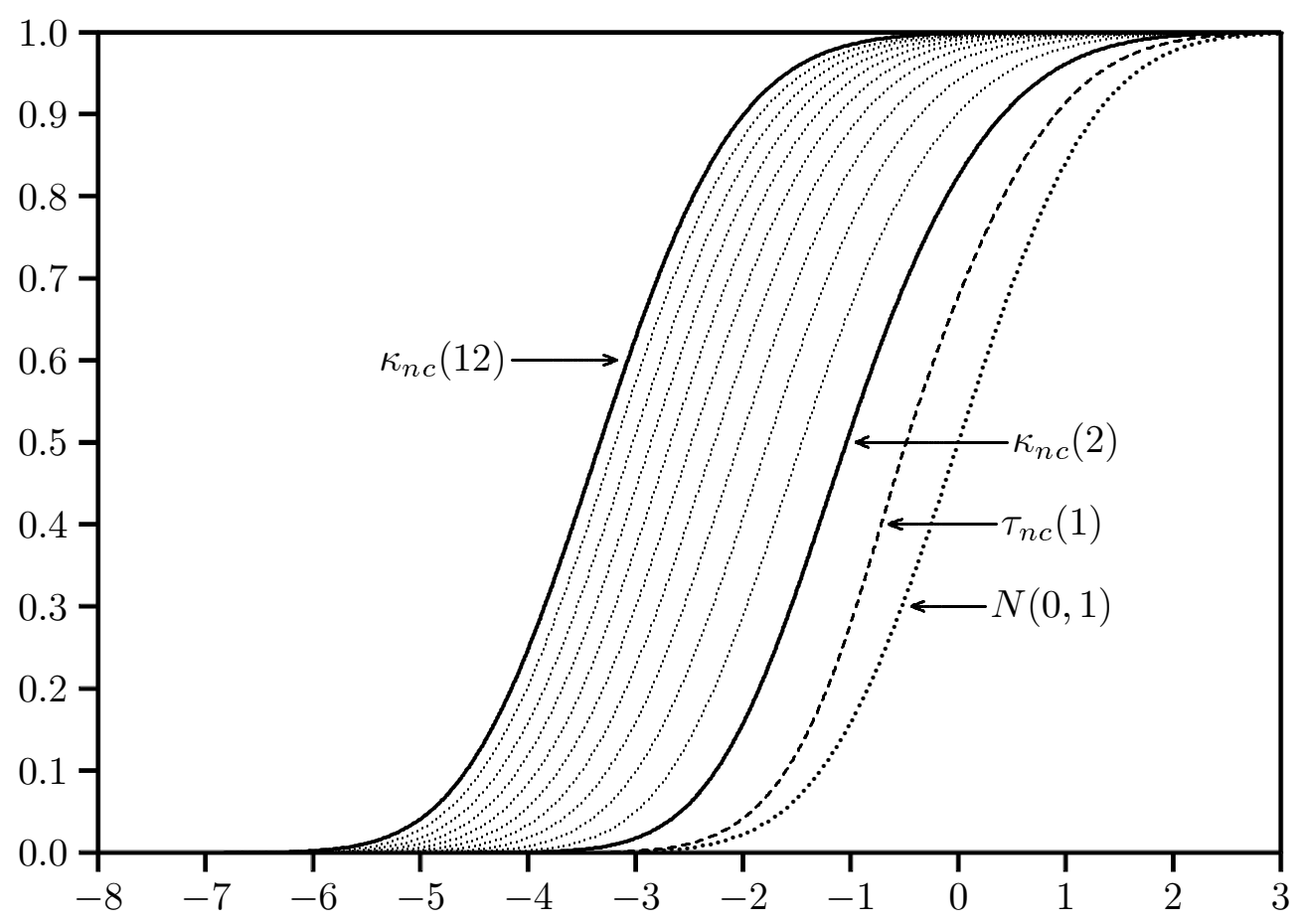

Figure 1: CDFs of the ECM statistic: no constant.

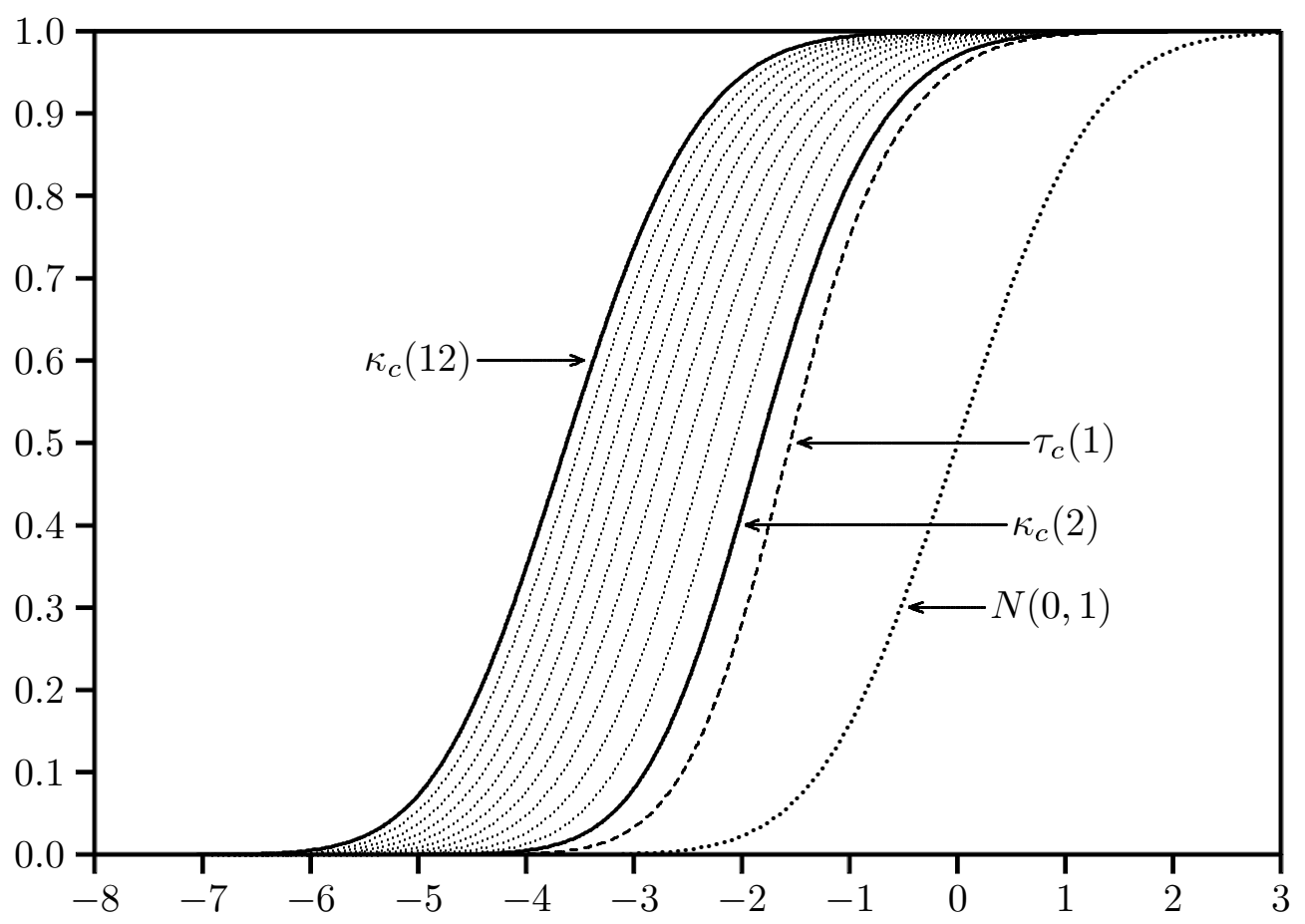

Figure 2: CDFs of the ECM statistic: constant only. 


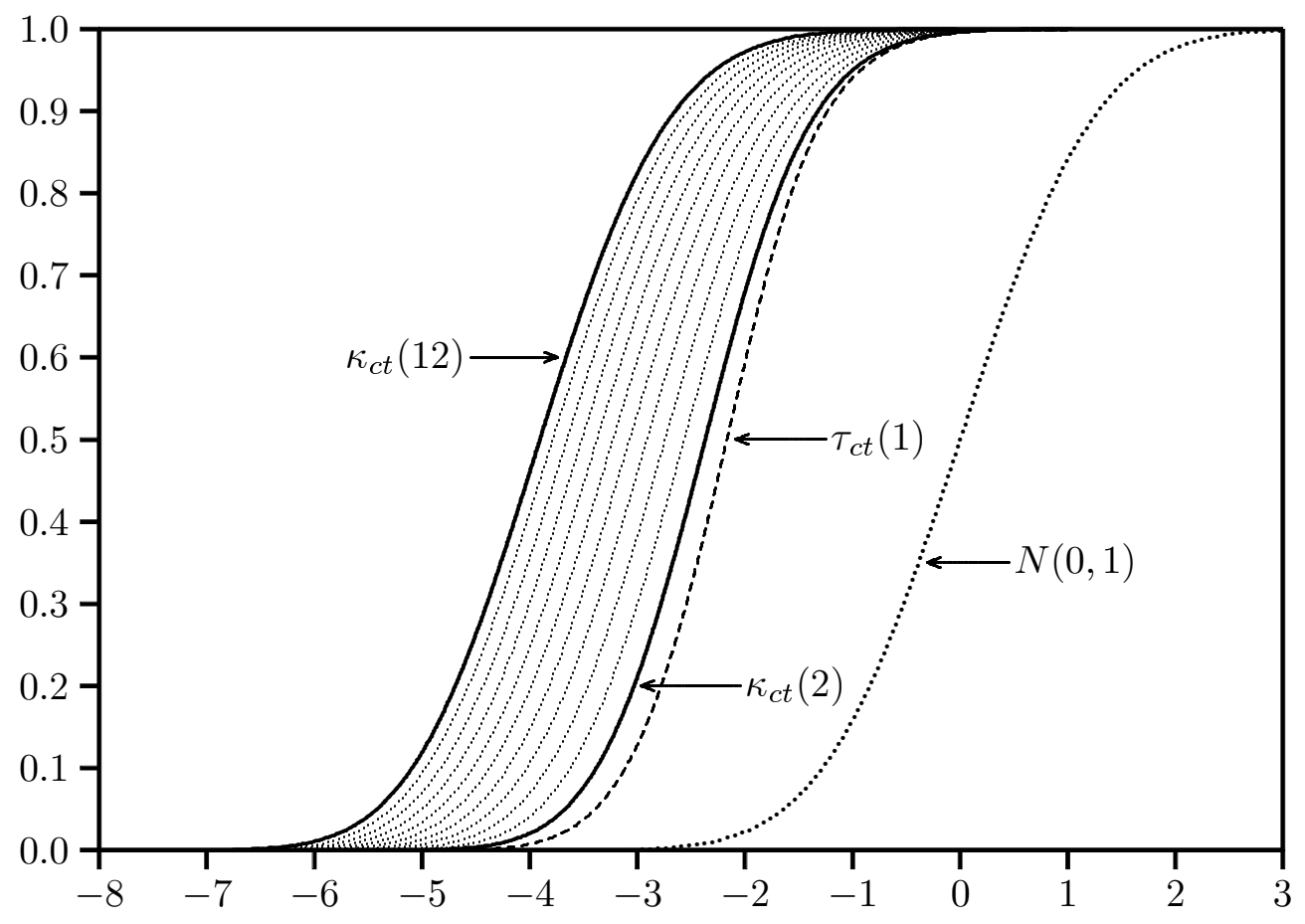

Figure 3: CDFs of the ECM statistic: constant and trend.

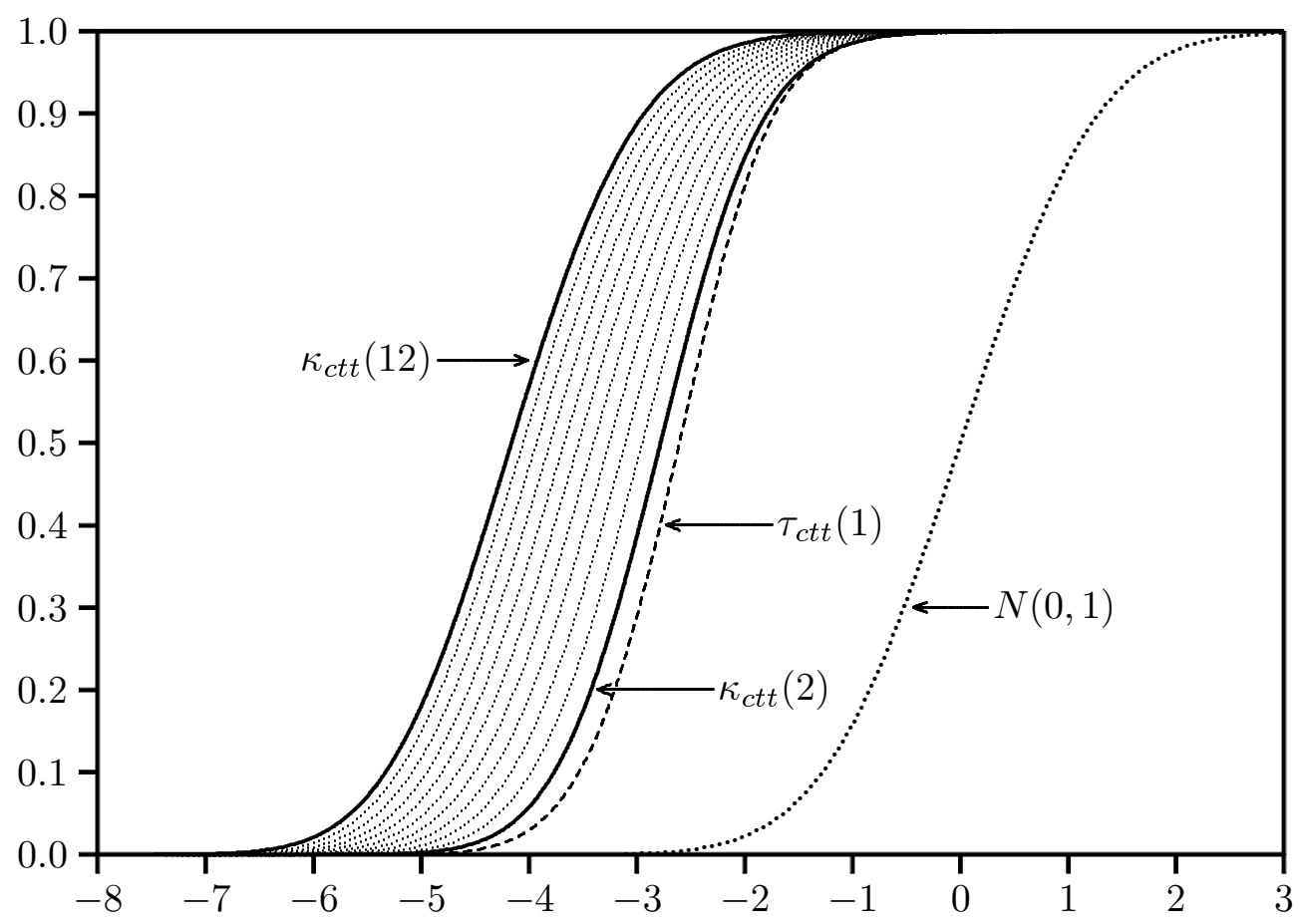

Figure 4: CDFs of the ECM statistic: constant, trend, and trend squared. 


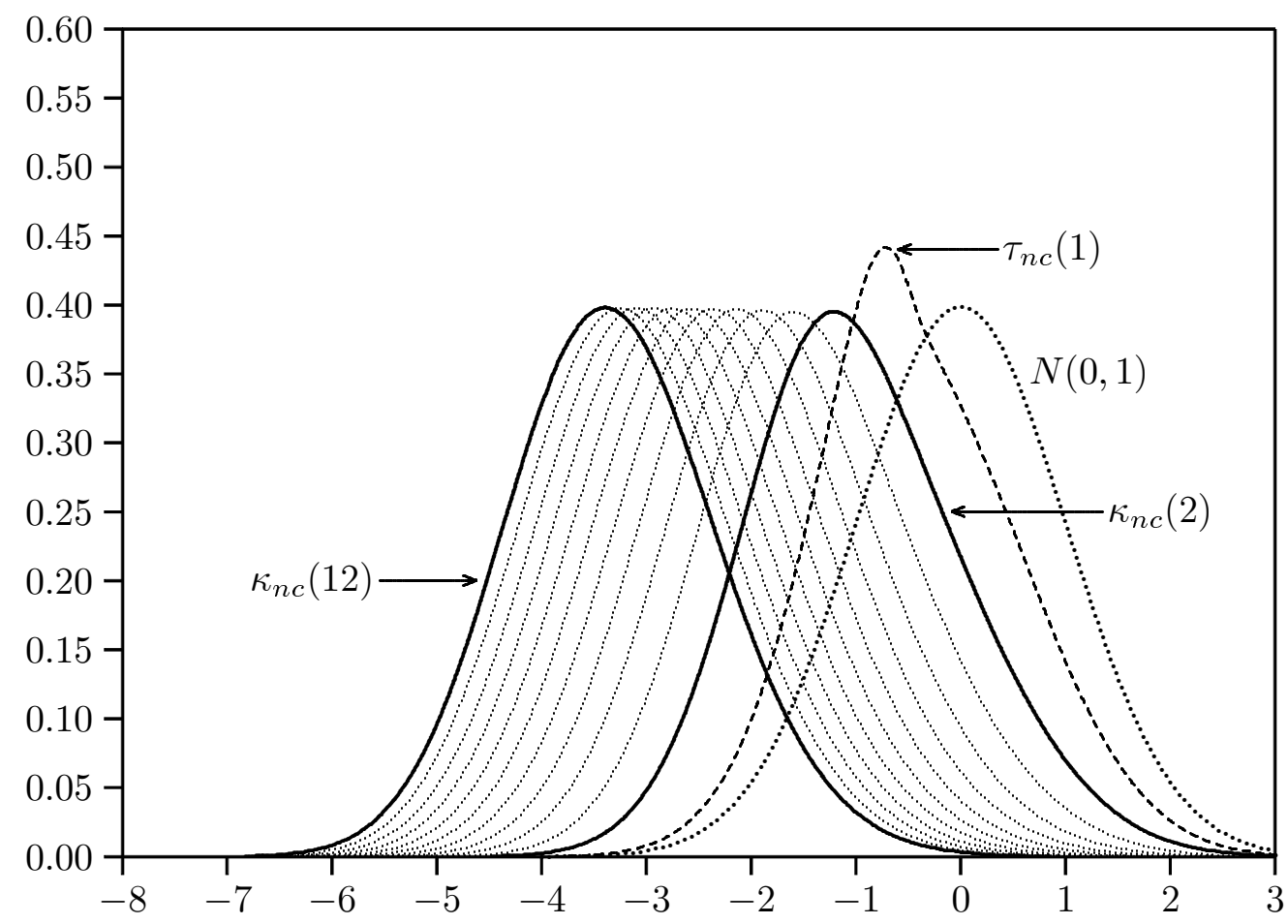

Figure 5: Densities of the ECM statistic: no constant.

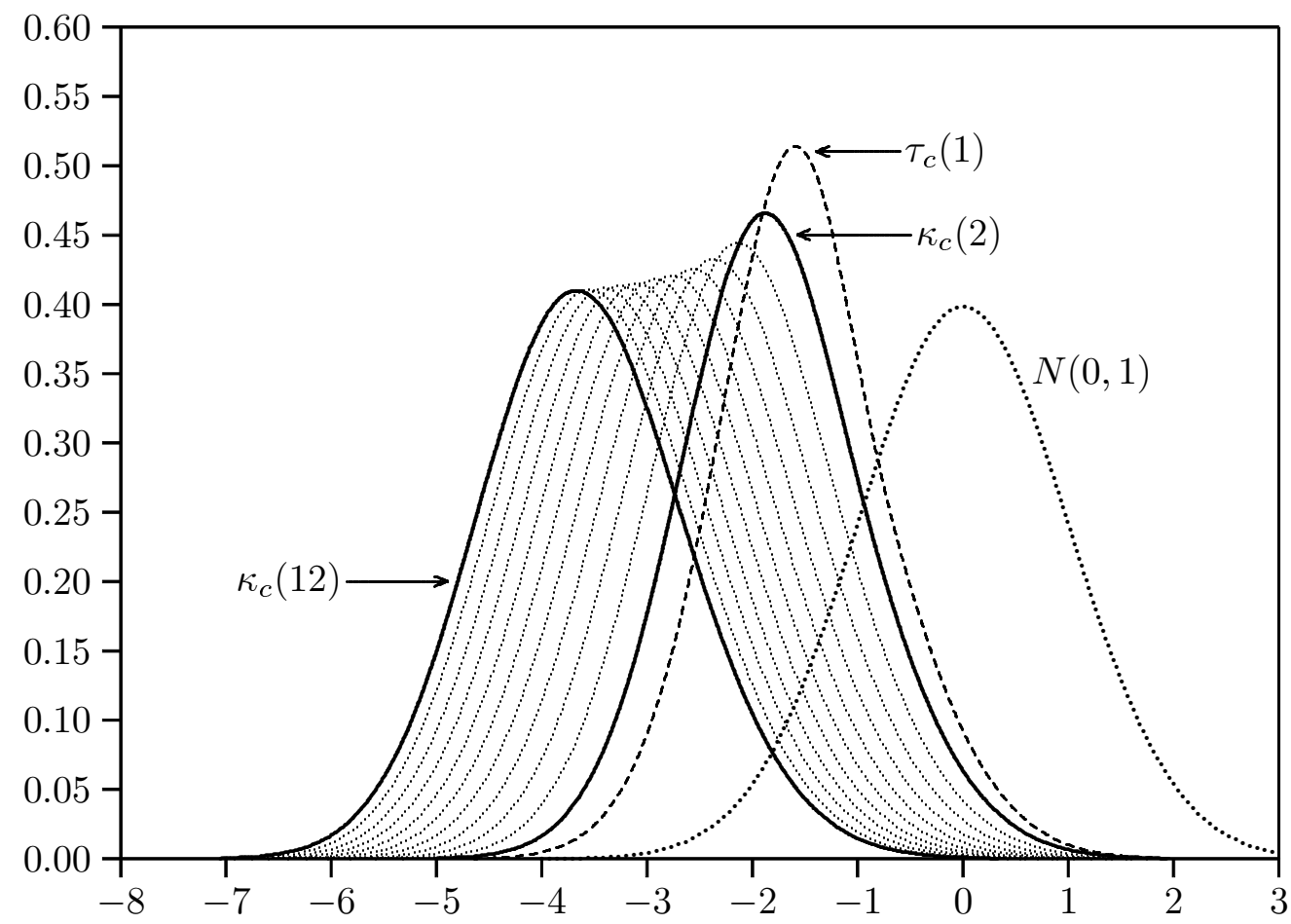

Figure 6: Densities of the ECM statistic: constant only. 


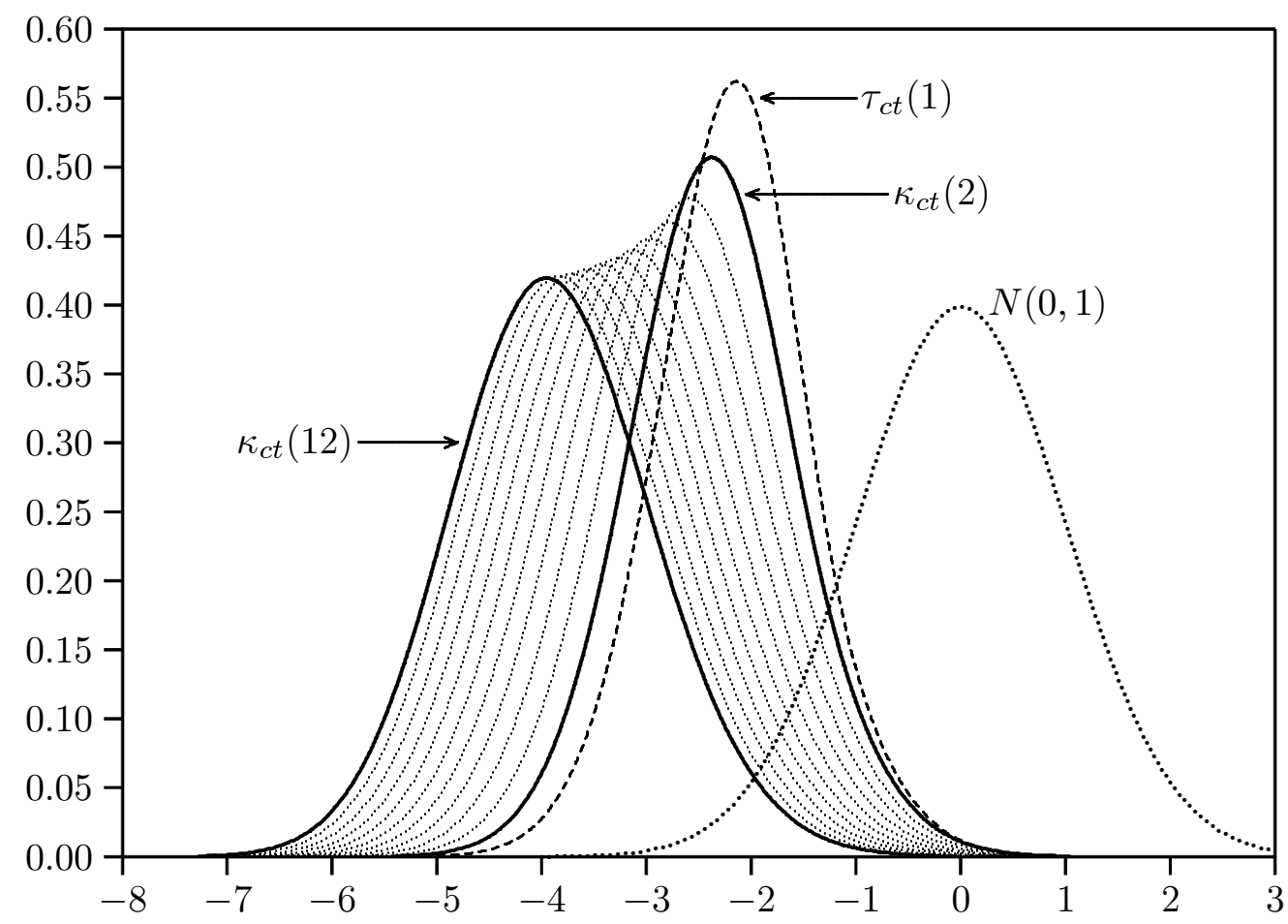

Figure 7: Densities of the ECM statistic: constant and trend.

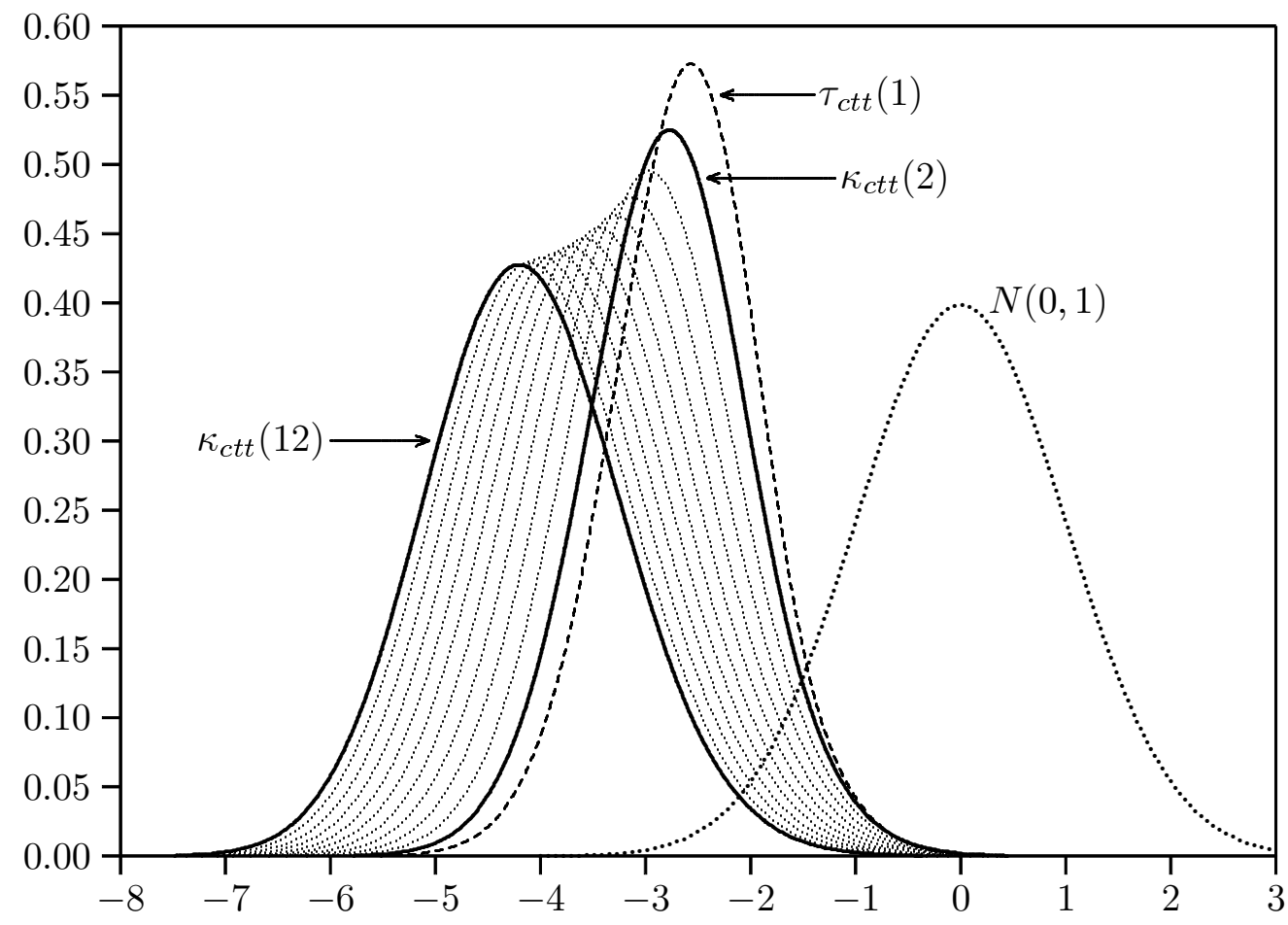

Figure 8: Densities of the ECM statistic: constant, trend, and trend squared. 


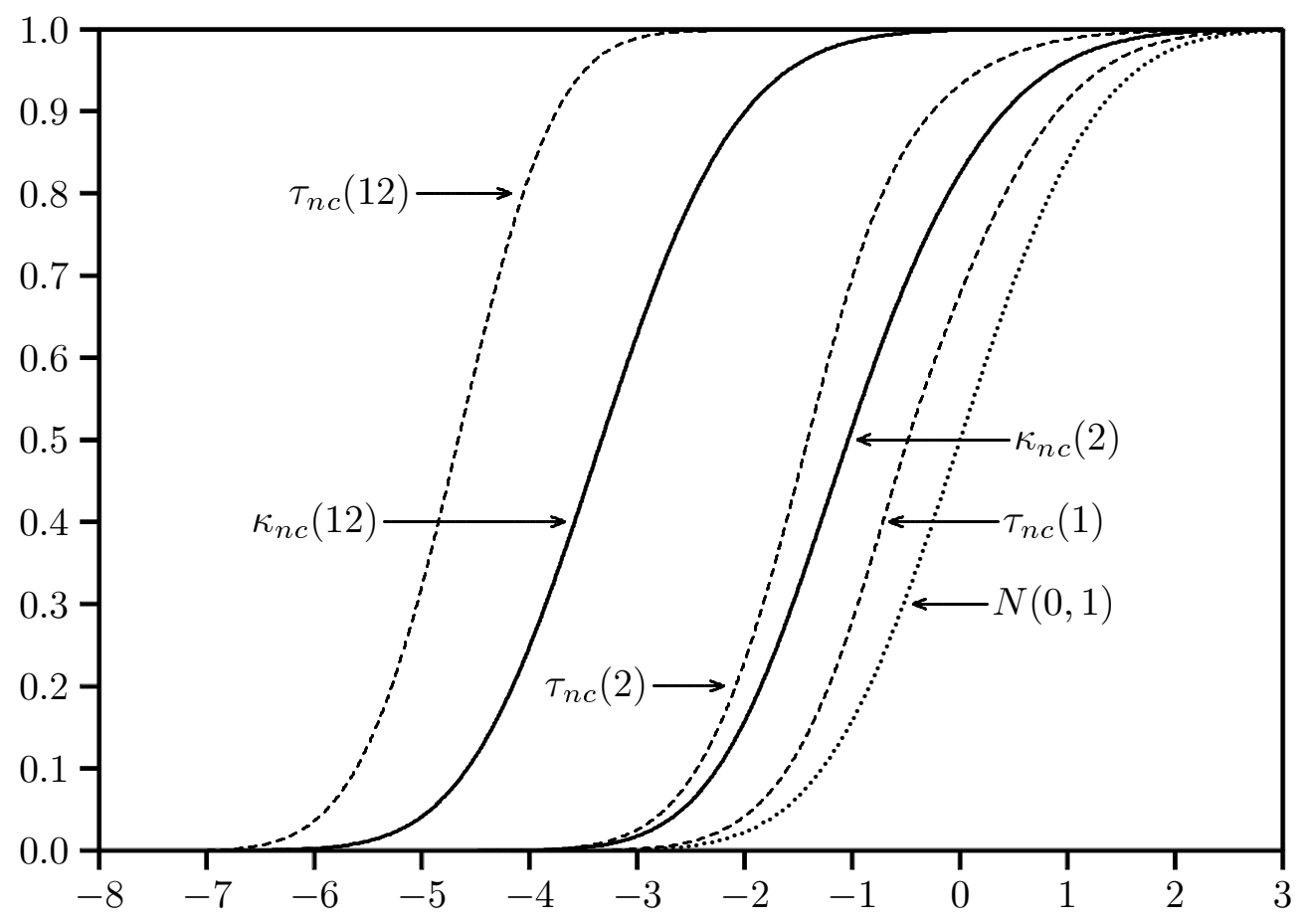

Figure 9: CDFs of the ECM and EG statistics: no constant.

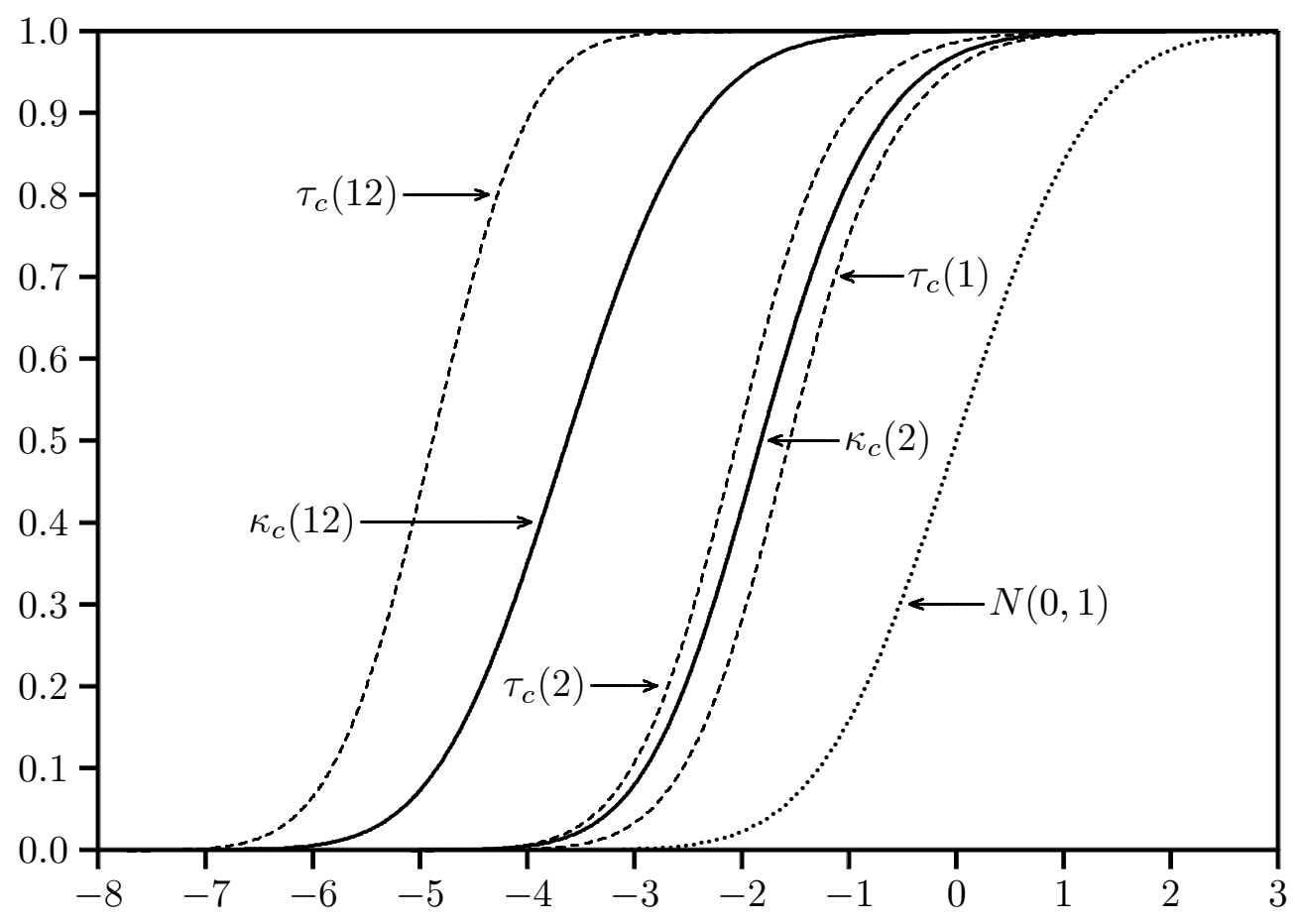

Figure 10: CDFs of the ECM and EG statistics: constant only. 


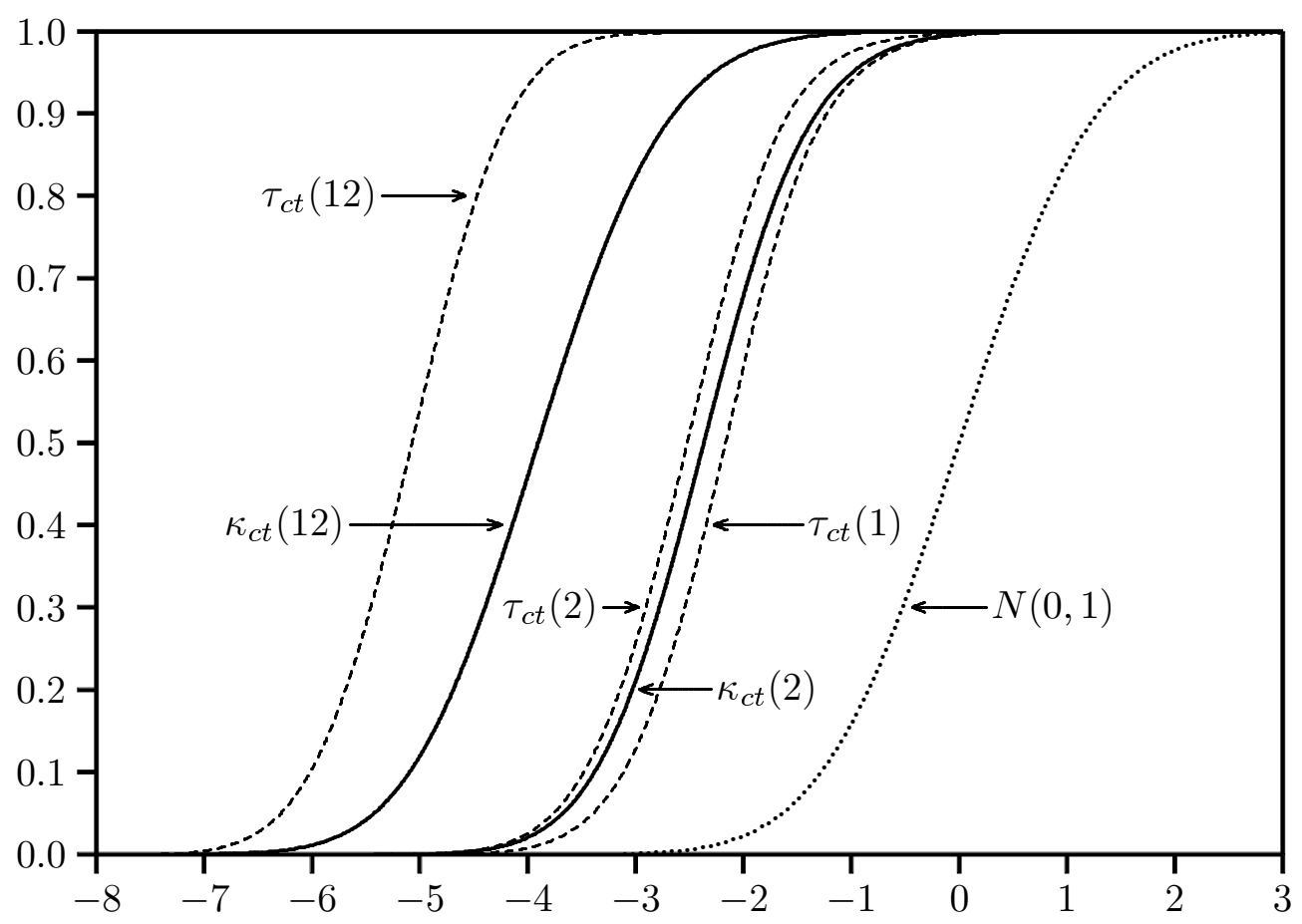

Figure 11: CDFs of the ECM and EG statistics: constant and trend.

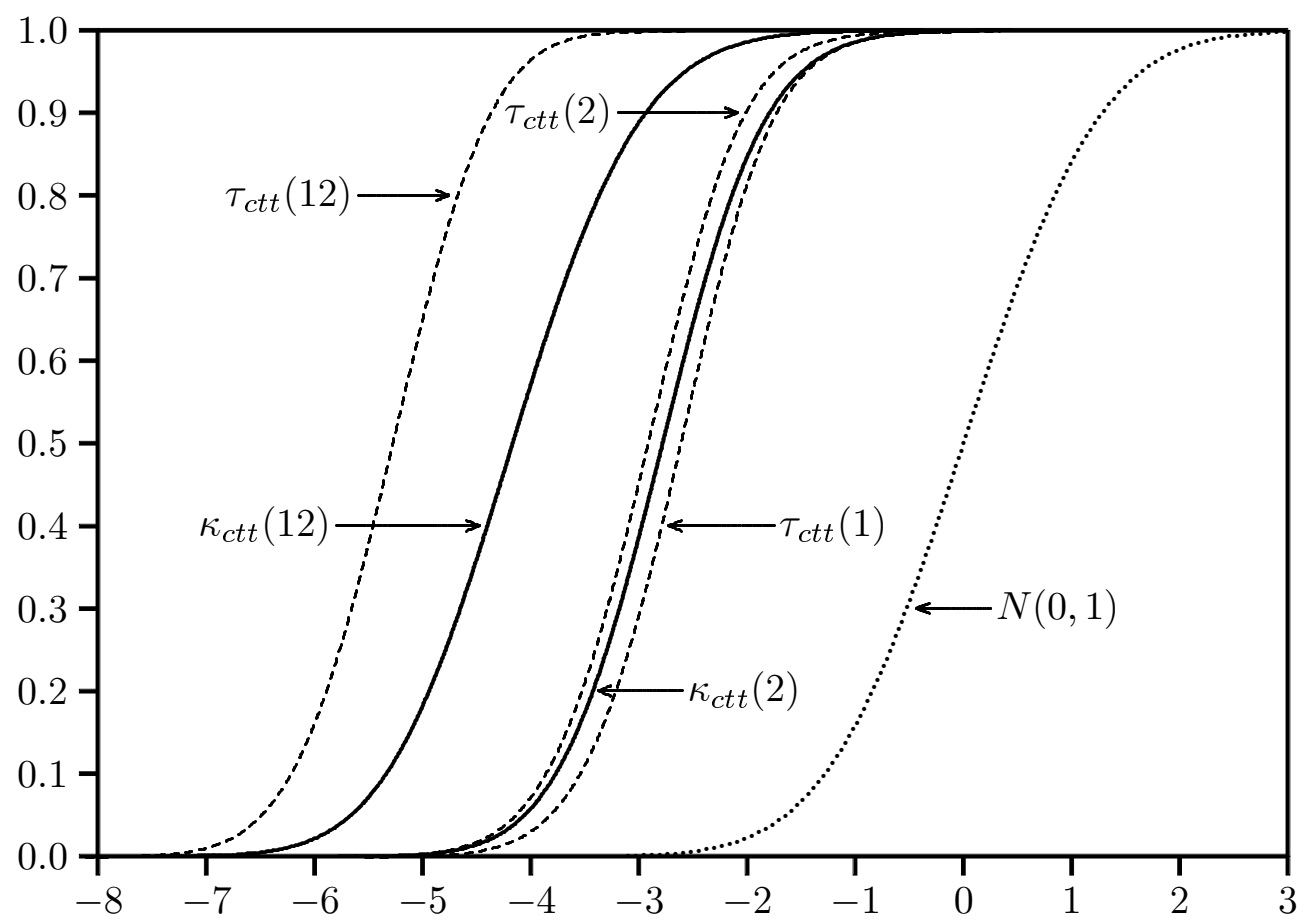

Figure 12: CDFs of the ECM and EG statistics: constant, trend, and trend squared. 


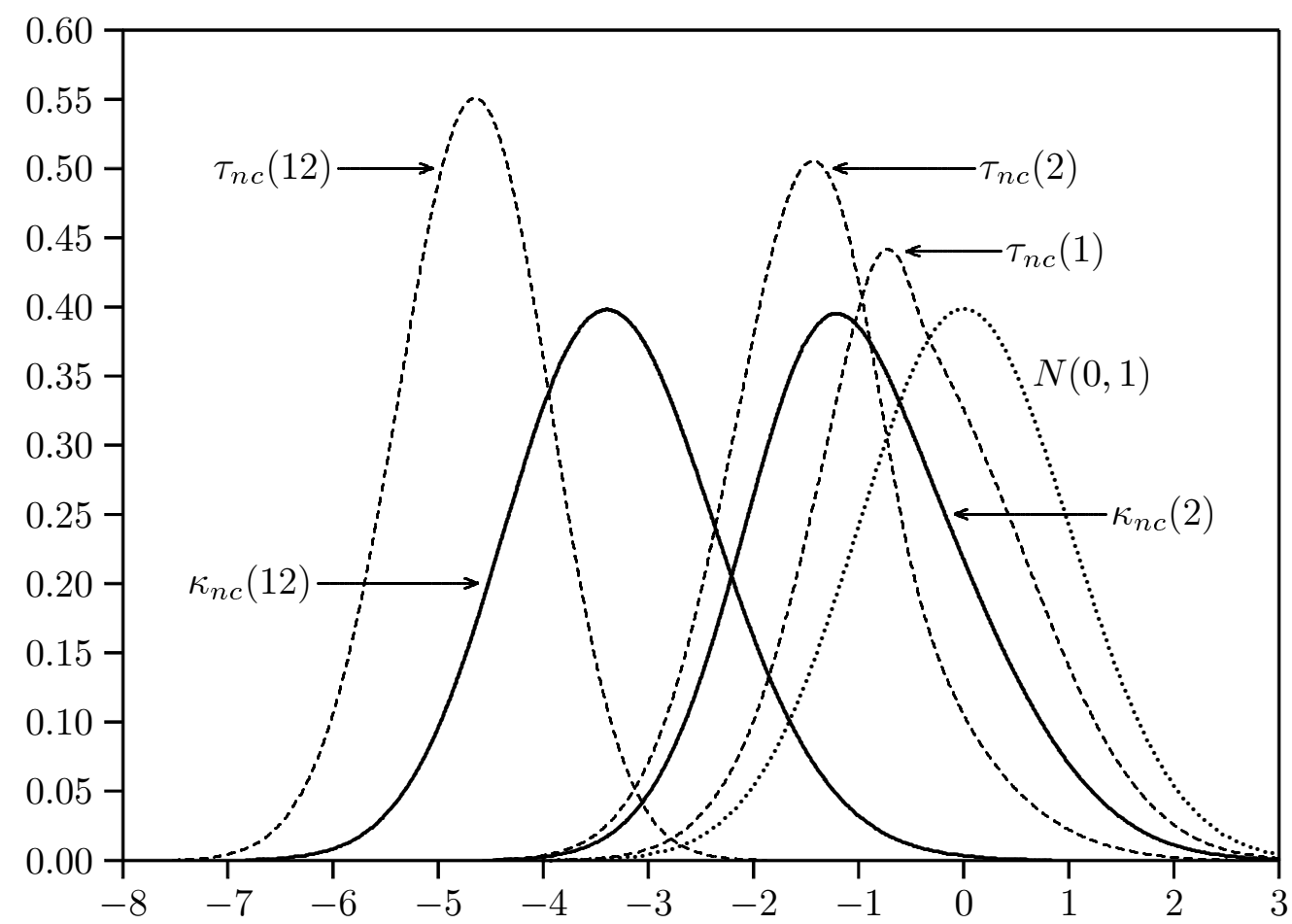

Figure 13: Densities of the ECM and EG statistics: no constant.

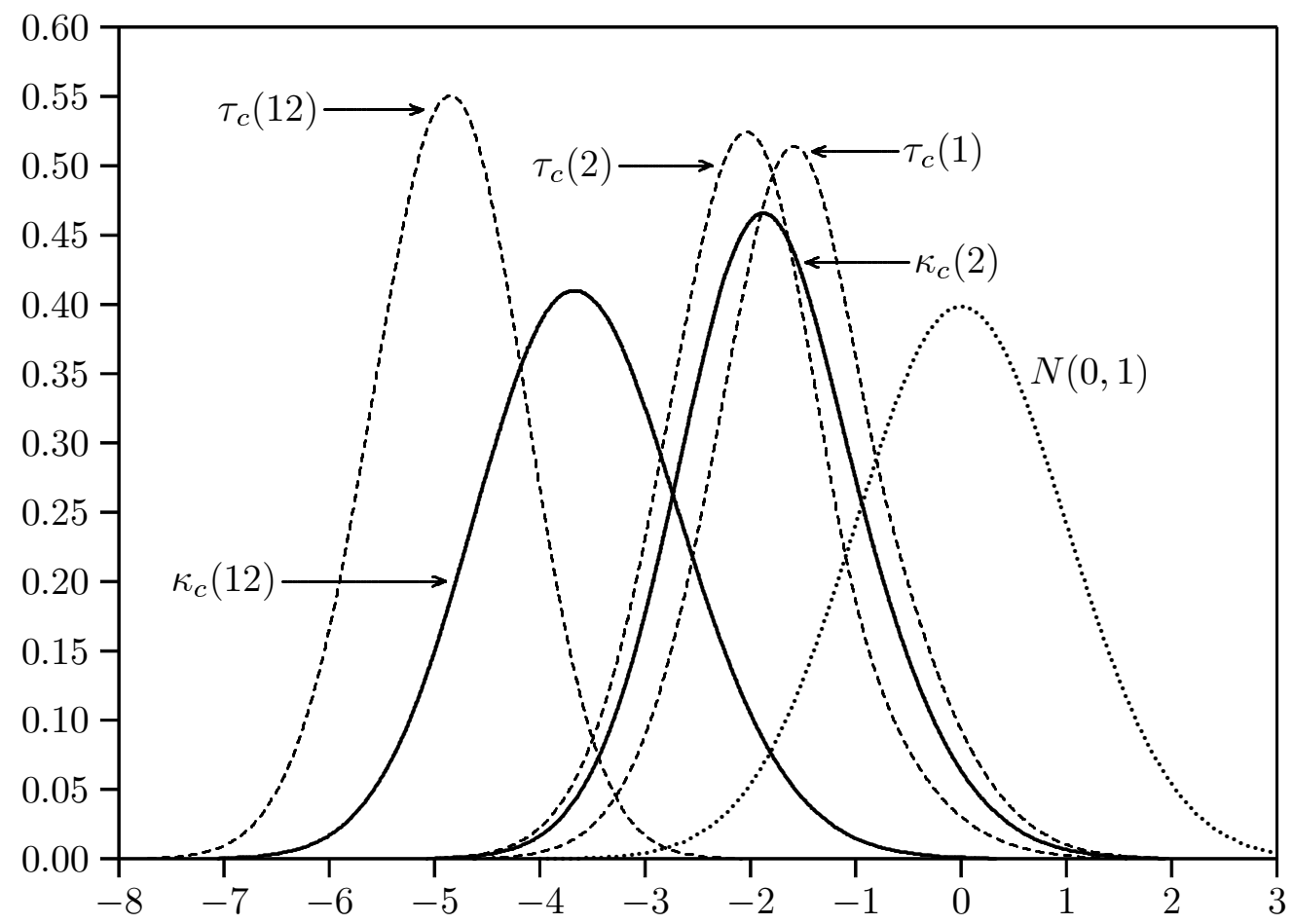

Figure 14: Densities of the ECM and EG statistics: constant only. 


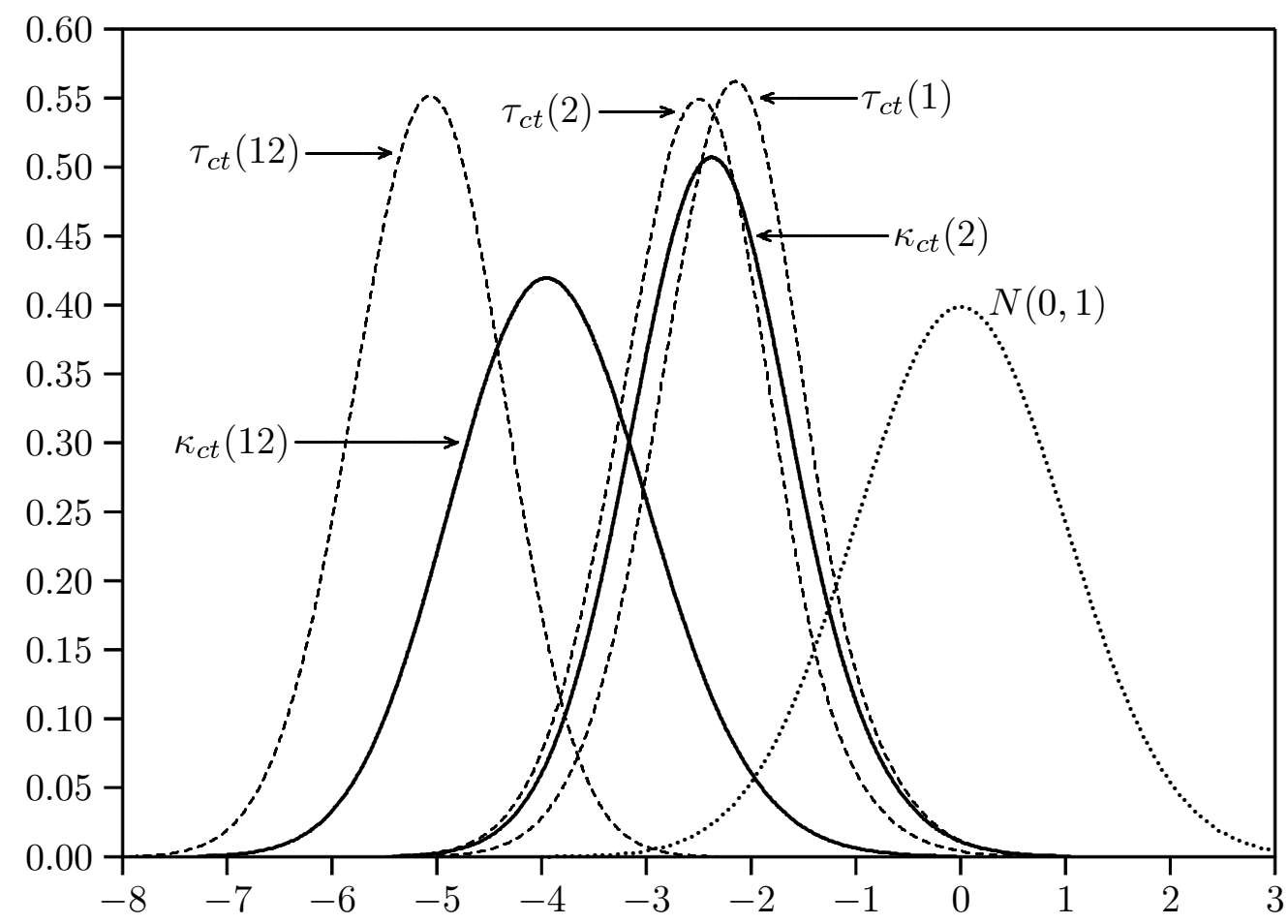

Figure 15: Densities of the ECM and EG statistics: constant and trend.

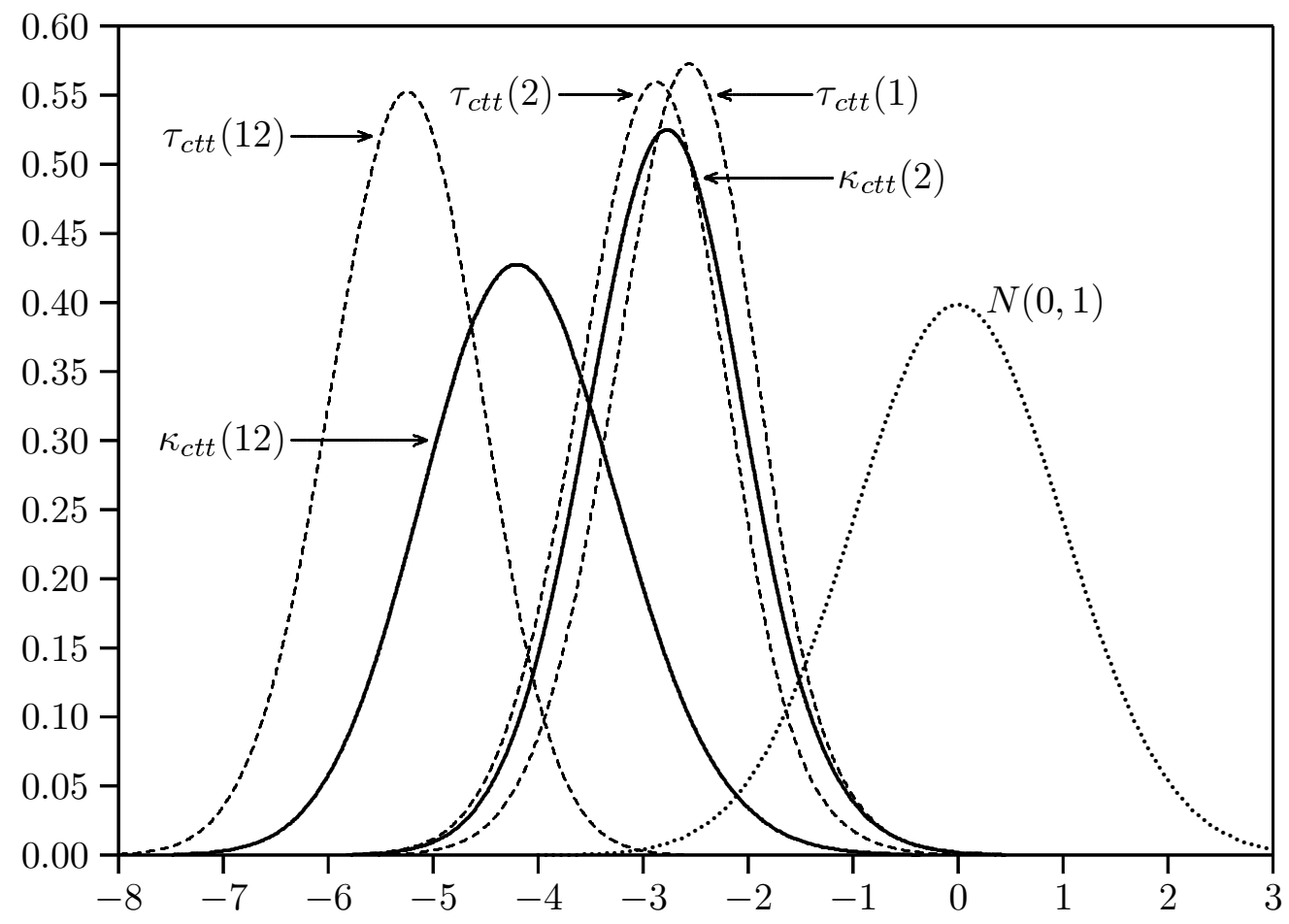

Figure 16: Densities of the ECM and EG statistics: constant, trend, and trend squared. 


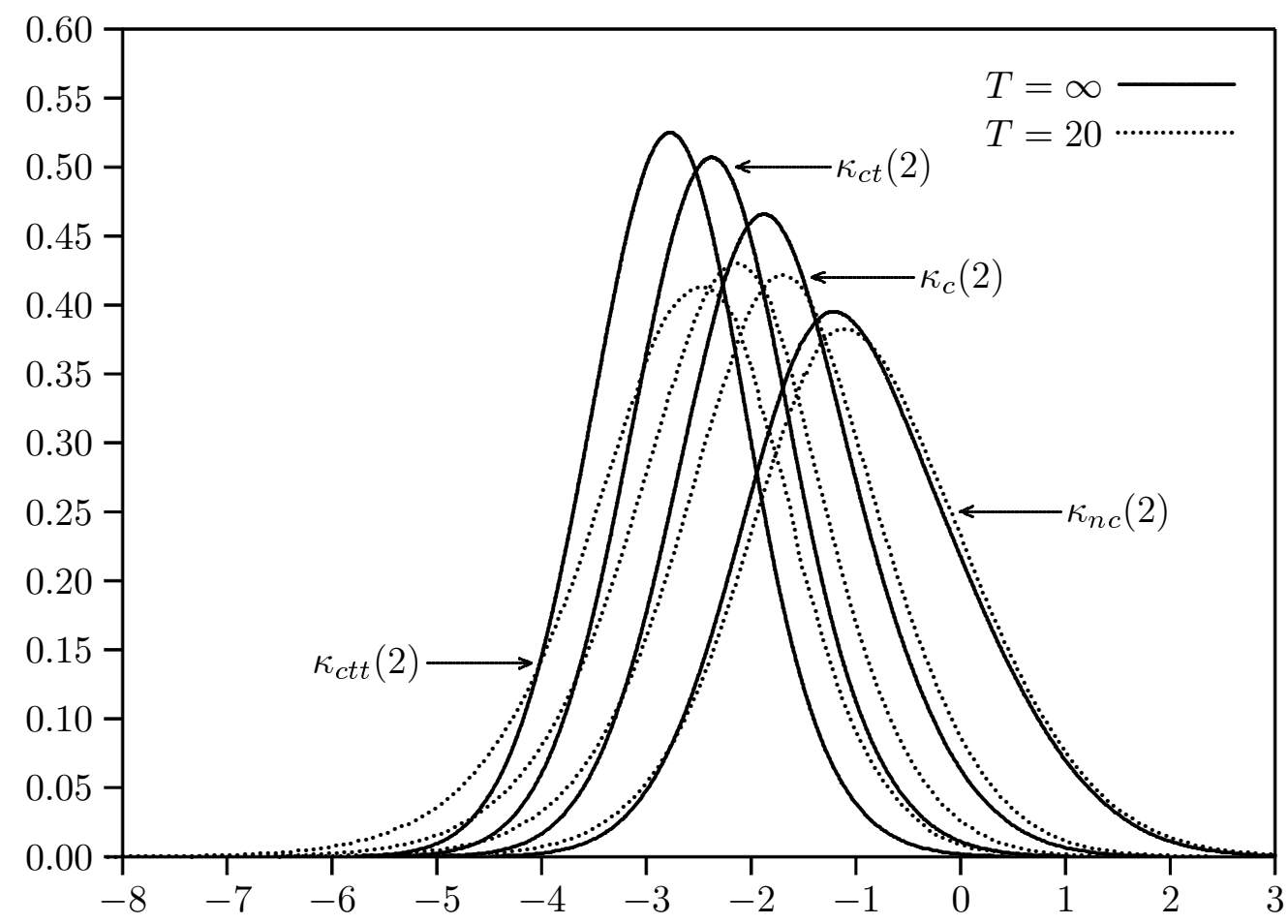

Figure 17: Asymptotic and finite sample densities of the ECM statistic: $k=2$.

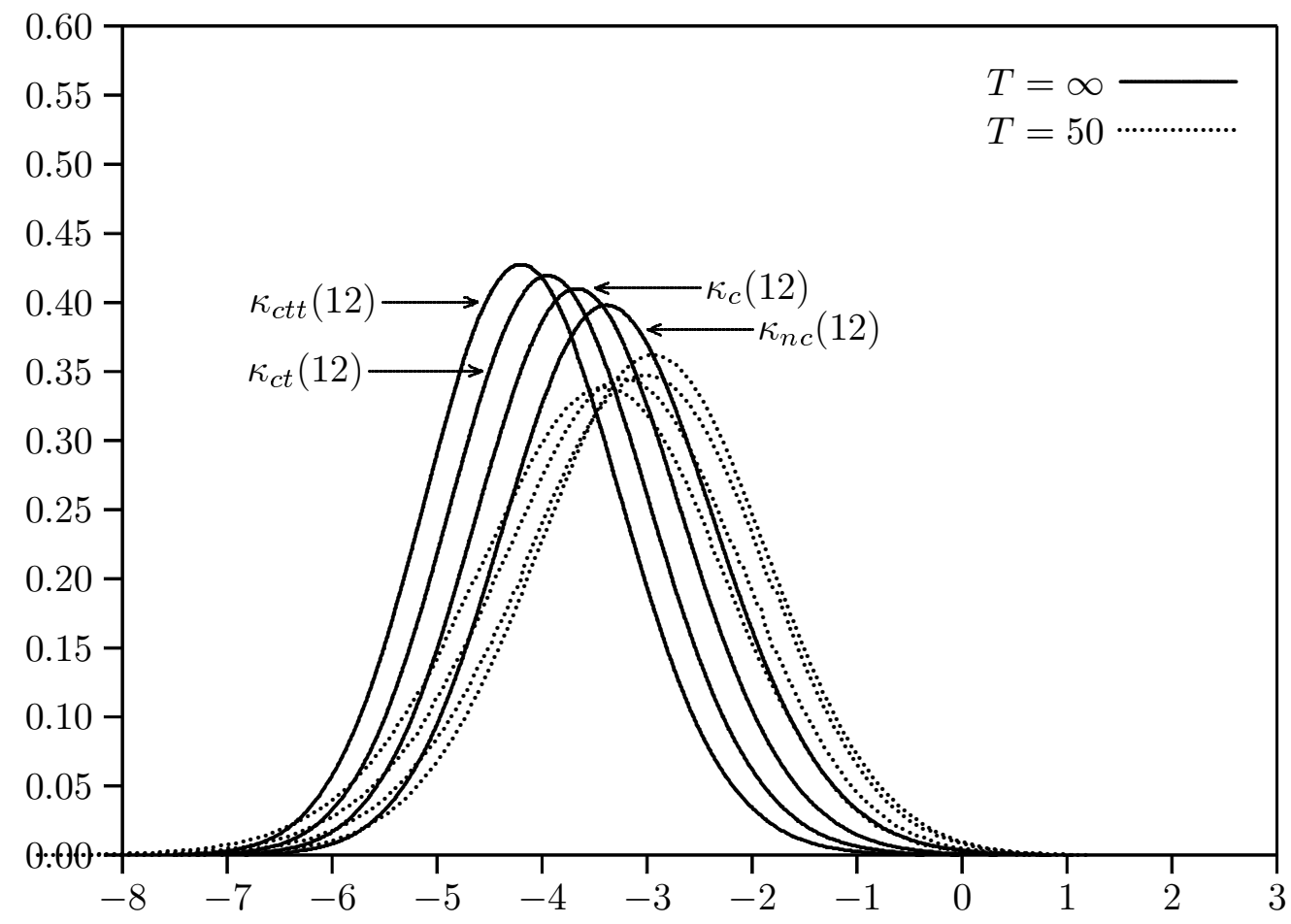

Figure 18: Asymptotic and finite sample densities of the ECM statistic: $k=12$. 
$1 \%$ level
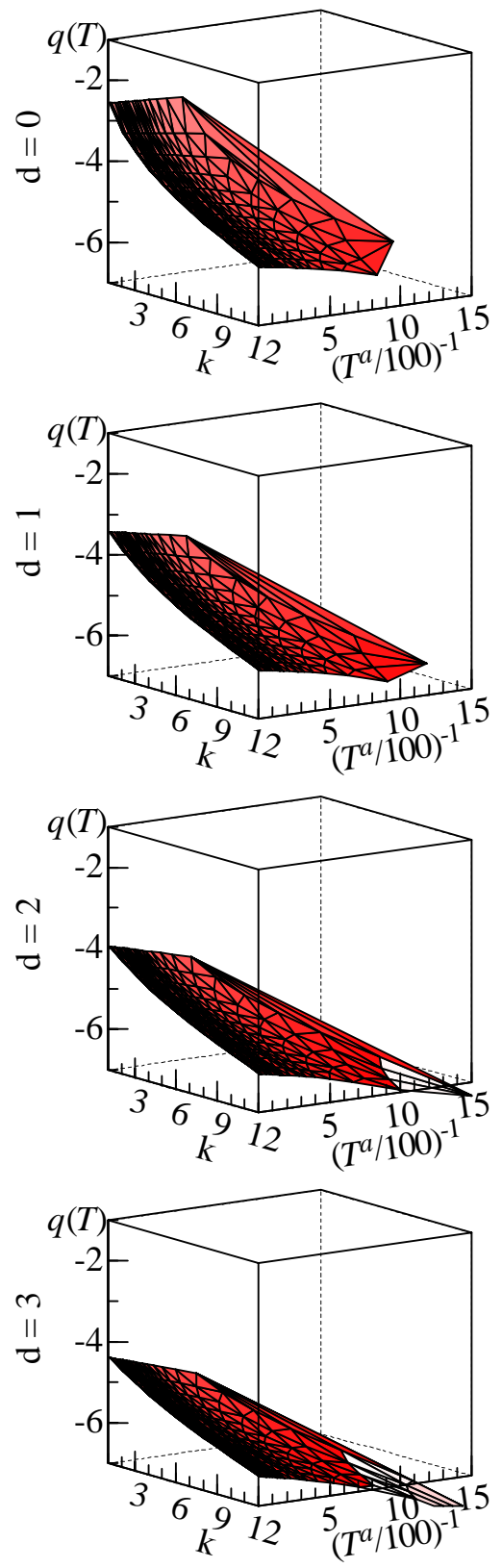

$5 \%$ level
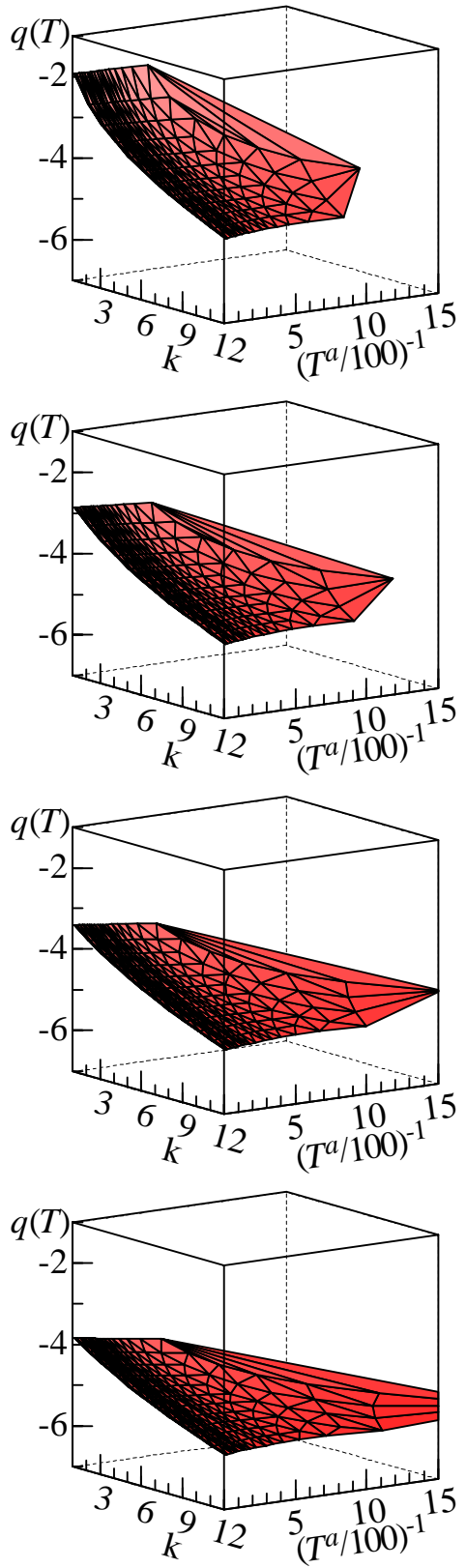

$10 \%$ level
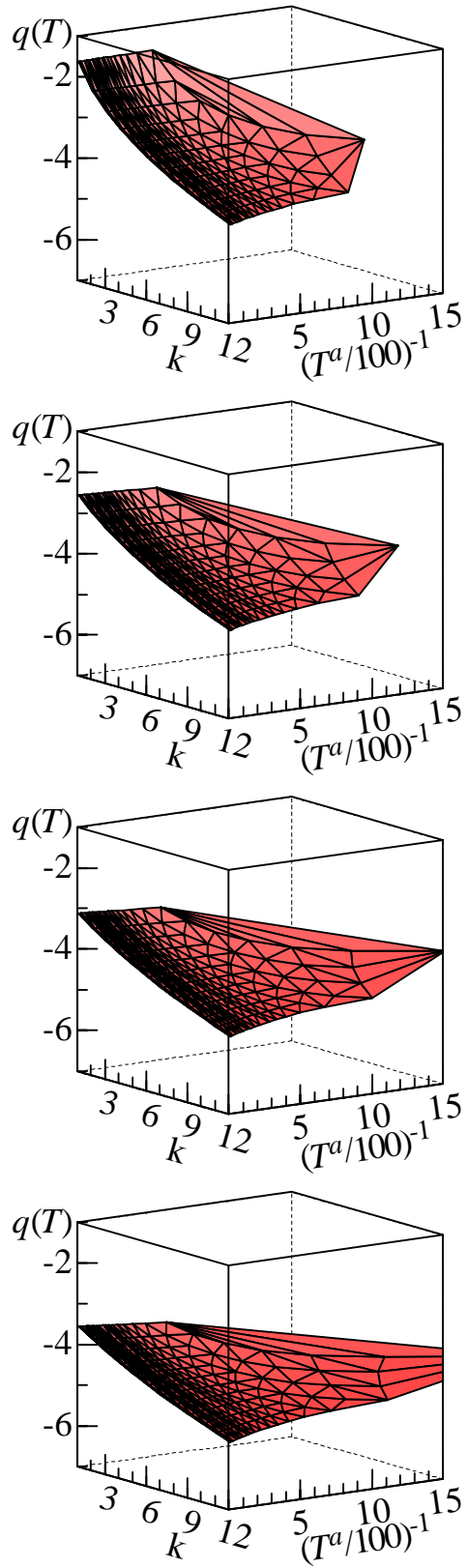

Figure 19: Estimated finite sample 1\%, 5\%, and $10 \%$ quantiles $q(T)$ for the ECM statistic as a function of $d, k$, and $T^{a}$. 

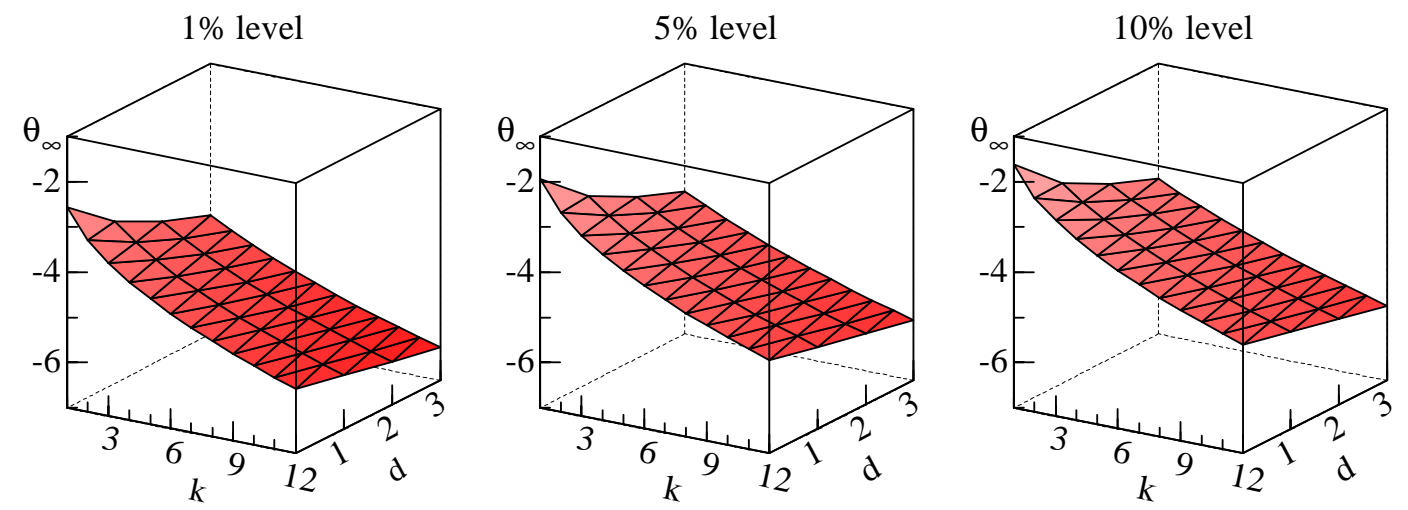

Figure 20: Estimated asymptotic $1 \%, 5 \%$, and $10 \%$ quantiles $\theta_{\infty}$ for the ECM statistic as a function of $k$ and $d$. 